\title{
Compromissum. Su naturaleza jurídica
}

\author{
Dr. Jesús Daza Martínez
}

\section{OBSERVACIONES PRELIMINARES}

Este instituto, cuya evolución histórica había sido expuesta ya a finales del siglo XIX,' fue estudiado posteriormente desde una perspectiva distinta, intentando determinar cuál es la estructura interna del mismo.

En este empeño destaca sin duda el esfuerzo de M. Talamanca, ${ }^{2}$ a finales de los años cincuenta, por someter a revisión los resultados a que habían llegado autores como G. Rotondi, ${ }^{3} \mathrm{~J}$. Roussier ${ }^{4} \mathrm{y}$, en particular G., La Pira. ${ }^{5}$

Este último romanista había mantenido la tesis de que la forma común de concebir en la doctrina romanística ese compromissum debía considerarse errónea. Tal concepción puede concretarse brevemente en los puntos siguientes: se trataría de un pactum mediante el cual las partes sometían al juicio de un tercero (arbiter) la decisión de un litigio. Supuesto que la setencia del arbiter no obligaba a las partes, éstas se habrían obligado anteriormente recurriendo a dos estipulaciones penales recíprocas que, por tanto, presuponían ya concluido el compromissum y se ordenaban a garantizar de forma indirecta su eficacia práctica. ${ }^{6}$

La Pira piensa que no es aceptable esta doctrina, en cuanto que el compromissum sería en realidad un negocio formal constituido por dos estipulaciones interdependientes mediante las cuales las partes someten a un arbiter, elegido de común acuerdo, una controversia existente entre ellos y solemnemente delimitada en la fórmula misma de la estipula- 
ción, obligándose a cumplir la sentencia. Intentando precisar más su pensamiento, el autor observa que «ciò che ha sviato la dottrina è il fatto che essa, supponendolo unico, ha rivolto costantemente il suo sguardo allo scopo penale delle due stipulazioni: senza accogersi che accanto ad esso, e enzi prima di esso, queste due reciproche stipulazioni ne ponevano un altro: quello, cioè, di fissare solennemente i termini della controversia sottoposta alla decisione dell' arbitro, in guisa da segnare a costui un programma preciso cui attenersi nel giudicare». ${ }^{7}$

Prolongando esta reflexión, observa que, supuesto este error de perspectiva, era normal que se llegara a una incomprensión del proceso arbitral. En efecto, al concebirse el compromissum como pactum, a cuya naturaleza se conformaba un libre planteamiento de las controversias, el paralelismo estructural del proceso arbitral con el proceso ordinario "doveva restare necessariamente nell' ombra». ${ }^{8}$

Supuestas estas consideraciones, la clave de la concepción del compromissum que defiende La Pira radica en las proposiciones siguientes: a) el compromissum no es un pacto al que se añaden extrínsecamente dos estipulaciones penales, sino un negocio formal que se realiza mediante dos estipulaciones interdependientes que tienen como objeto el someter una determinada controversia a la decisión de un arbiter y la obligación recíproca de la partes de cumplir la sentencia; b) el planteamiento de la controversia en la fórmula misma de las estipulaciones se hacía según esquemas idénticos a los que se empleaban en la litis contestatio; c) esto supuesto, el mismo paralelismo que existe entre litis contestatio y compromissum puede encontrarse también entre el iussum iudicandi y el receptum arbitrii, entre la sentencia judicial y la arbitral.

Inmediatamente antes de la toma de posición crítica de Talamanca frente a esta concepción del compromissum, a la que haremos referencia, había ya observado F. Bonifacio que sólo dentro de márgenes muy restringidos puede hablarse de un paralelismo entre compromissum y iudicium. Y añadía que «sembra anche azzardato ricondurre a principi unitari i due istituti e respingere in secondo piano quella che del compromissum è invece la caratteristica principale». ${ }^{9}$ Según él, la única obligación que surge del compromissum tiene por objeto el pago de la pena y, respecto a tal vínculo, la inobservancia de la sentencia tiene só- 
lo el papel de condición: de la decisión no nace la actio iudicati en ninguna época del derecho romano. ${ }^{10}$

\section{EL PROBLEMA DE LA ESTRUCTURA DEL COMPROMISSUM}

\subsection{Compromissum y iudicium}

La posición mantenida por La Pira, en el sentido de que existían unos esquemas fijos de compromiso y que tales esquemas eran idénticos a los de los iudicia en el procedimiento formulario, fue sometida a una crítica muy matizada y precisa por parte de Talamanca.

En primer lugar, y tras señalar que su planteamiento no encuentra base en las fuentes, observa que La Pira no distingue entre «solemnità che deriva al compromissum dal consistere, secondo l'ulteriore requisito formale, che l'autore presuppone, e che, in analogia a quanto avviene per i iudicia dell'ordo, dovrebbe riscontrarsi nell'onere di adibizione di particolari verba solemnia nella configurazione delle formule stipulatorie». ${ }^{11}$ Por otra parte, se resalta el hecho de que, sea cual sea la valoración de las relaciones entre conventio compromissi y stipulationes, y la función para la que son usadas, es evidente que las partes deben someterse a los onera que impone el uso de la forma estipulatoria. Pero La Pira no aporta ninguna prueba del ulterior requisito formal de que las partes, al configurar las estipulaciones debían emplear determinadas verba. ${ }^{12}$

La posición crítica de Talamanca es fundamentada por él contraponiendo el esquema de compromissum finium regundorum propuesto por La Pira ${ }^{13}$ con el que ha sido conservado en las Tabulae Hercolanenses, ${ }^{14}$ a propósito de una controversia finium regundorum.

Lo que resalta inmediatamente es el hecho de que la reconstrucción que propone La Pira contradice a lo que él mismo afirma, en cuanto que no reproduce el tenor de la formula finium regundorum, en cuya demonstratio se recordaba la postulatio iudicis vel arbitri; sin embargo, se inspira en el fundamento de esa formula, que teniendo su origen en la legis actio per iudicis arbitrive postulationem, «si impernia appunto sulla postulatio iudicis, che, nel compromissum, viene invece sostituita 
del ricordo del'electio arbitri». ${ }^{15}$ En cualquier caso, el hecho evidente es que en el pasaje citado de las Tabulae Hercolanenses, y que probablemente es un formulario tomado de la jurisprudencia cautelar, no se hace ninguna referencia al esquema de la formula del procedimiento ordinario. Tampoco se alude a la elección del arbiter como fundamento del procedimiento y su actividad decisoria es indicada simplemente con la expresión sententiam dicere. En este sentido, parece evidente que debe aceptarse la afirmación de Talamanca de que la configuración del compromissum en analogía con el iudicium recibe en este pasaje un desmentido pleno. ${ }^{16}$

La posición crítica de Talamanca respecto a la interpretación propuesta por La Pira, se concreta, más adelante, en su toma de posición a propósito del alcance que debe darse al siguiente pasaje de Paulo:

Compromissum ad similitudinem iudiciorum redigitur et ad finiendas lites pertinet. $^{17}$

La Pira interpreta el pasaje en el sentido de que el compromissum aparece configurado en su forma estipulatoria, de igual modo que el iudicium, mientras que Talamanca observa que, desde el punto de vista literal, el único sentido que puede tener la expresión redigitur es que el compromissum, en lo que se refiere al tratamiento jurídico entra dentro de la categoría del iudicium, es decir, es regulado, en algunos aspectos, por las mismas normas que regulan el iudicium en el proceso ordinario, pero esto no significa que presente una forma exterior análoga a la del iudicium mismo.

Otro texto que parece favorecer la opinión de La Pira se encuentra en un pasaje del pro $Q$. Roscio de Cicerón en que parece establecerse una cierta semejanza entre la forma de la litis contestatio y la del compromissum:

Ei ipsa verba formulae testimonio sunt.Quid est in iudicio? Derectum, asperum, simplex: si paret H S dari. Hic nisi planum facit H S ad libellam sibi deberi, causam perdit. Quid est in arbitrio? Mite, moderatum: quantum aequius et melius sit dari. ${ }^{2}$

Basándose en este texto, autores como Broggini ${ }^{19}$ piensan que si Cicerón empleaba la fórmula quantum aequius melius sit dari, propia del 
arbitrium honorarium pro socio, también para el arbiter ex compromisso, esto significaría que las instrucciones para el arbiter addictus y para el arbiter ex compromisso no eran muy diferentes. Talamanca piensa que esta forma de argumentar carece de suficiente fundamento pero reconoce, de acuerdo con una opinión dominante hoy, que el proceso entre Roscius y Fannius se habría desarrollado en la forma del arbitraje privado y no en la del procedimiento ordinario. ${ }^{20}$ Aunque el término compromissum sea empleado por Cicerón también en relación con negocios que no tienen la forma estipulatoria, no puede sino referirse a un negocio que dé lugar a un procedimiento arbitral privado, esto es, nunca puede referirse a la litis contestatio de un procedimiento per formulam. ${ }^{21}$

El desacuerdo de Talamanca con la posición de Broggini a propósito de la interpretación del pasaje de Cicerón tiene lugar sobre todo en relación con el significado preciso que deba atribuirse a la expresión quantum aequius melius sit dari repromittique. Mientras que Broggini entiende que tal expresión correspondería a la intentio incerta de la actio pro socio, tal como estaba configurada en los tiempos de Cicerón, existiendo, por tanto una correspondencia entre formula, en la que se realizaba la litis contestatio, y compromissum, Talamanca piensa que la interpretación del pasaje de Cicerón debe ser otra. Según él, es muy probable que el orador quisiera únicamente contraponer el carácter de estricto derecho de la acción ejercitada (la certae creditae pecuniae) y el carácter de buena fe de la ejercitada en el proceso arbitral precedente. En otras palabras, el quantum aequius... sirve para determinar la pretensión deducida en el compromissum, «pero no importa que tal frase debiera estar necesariamente en éste». ${ }^{22}$ Las partes, en efecto, para deducir en el arbitraje los derechos que se derivaban del contrato de sociedad no tenían obligación de referirse a la intentio de la formula pro socio, que Cicerón recuerda únicamente para indicar el carácter de buena fe de la pretensión de Fannius en relación con Roscius.

Esto supuesto, Talamanca piensa que pierde todo valor la contraposición que hace Cicerón entre iudicium y arbitrium. Se trataría únicamente de iustaponer los diversos efectos de la actio certae creditae pecuniae y de la actio pro socio, y habría empleado los términos iudi- 
cium y arbitrium como indicativos de uno y otro género de acción. En suma, no pretendía con el término arbitrium referirse a un aspecto particular del procedimiento arbitral.

\subsection{Pactum y compromissum}

Uno de los problemas más importantes suscitados por La Pira es el relativo a las relaciones entre conventio y stipulationes compromissi, al cual dio una solución radical que se concreta en esta afirmación: el compromissum clásico no es un pactum o conventio al cual se añadan, con la función de garantía, las recíprocas estipulaciones penales, sino un negocio formal, constituido por dos estipulaciones interdependientes que sirven para someter al arbiter la solución de una controversia y para obligar a las partes (de forma directa o indirecta, metu poenae) al cumplimiento de la sentencia.

Según él, si el compromissum hubiera sido un pactum al que se añadían extrínsecamente dos estipulaciones penales, deberían haber valido para él los principios que expone Ulpiano cuando dice:

Si pacto subiecta sit poenae stipulatio, quaeritur, utrum pacti exceptio locum habeat an ex stipulatu actio. Sabinus putat, quod est verius, utraque via uti posse prout elegerit qui stipulatus est: si tamen ex causa pacti exceptione utatur, aequum erit accepto eum stipulationem ferre. ${ }^{23}$

En suma, habría debido también surgir del compromiso una exceptio pacti derivada del compromissum como tal, en cuanto que pactum: nuda pactio... parit exceptionem, ${ }^{24}$ y una actio ex stipulatu derivada de la estipulación penal. Sin embargo es indudable que del compromissum, en el Derecho clásico no nacía la exceptio pacti. ${ }^{25}$

Supuesto, pues, que del compromissum no surge una exceptio pacti no puede decirse que sea un pactum en sentido técnico. Y, por el contrario, si nace de él una actio ex stipulatu, esto significa que la stipulatio es el medio con el cual se realiza el compromissum. ${ }^{26} \mathrm{Si}$ esto es así aparece evidente que el planteamiento de la controversia que va a someterse al arbiter debe conformarse a las exigencias de la fórmula estipulatoria. Ha de ser, pues, solemne y debe seguir ciertos esquemas abstractamente predeterminados y cognoscibles a priori. 
La afirmación de que el compromissum no es un pactum parece que se contradice con la mención que hace Ulpiano de una exceptio pacti en el pasaje siguiente:

Idem Pomponius scribit, si de meis solis controversiis sit compromissum et de te poenam sim stipulatus, videndum ne non sit compromissum [Sed cui rei moveatur non video: nam si ideo quia de unius controversiis solum compromissum est, nulla ratio est: licet enim et de una re compromittere: si vero ideo, quia ex altera dumtaxat parte stipulatio intervenit, est ratio, quamquam si petitor fuit qui stipulatus est possit dici plenum esse compromissum, quia is qui convenitur tutus est veluti pacti exceptione, is qui convenit, si arbitro non pareatur, habet stipulationem, sed id verum esse non puto: neque enim sufficit exceptionem habere ut arbiter sententiam dicere cogatur. ${ }^{27}$

En este texto, lo sustancial es la afirmación de que mientras es posible la conclusión de un compromiso en relación con las pretensiones de una sola de las partes, no es posible la conclusión de un compromissum con una sola stipulatio, ya que al concepto de compromissum le son esenciales las dos stipulationes recíprocas de las partes. La Pira observa que en el texto se insinúa la duda de si la exceptio pacti (que nace del compromissum en favor de la parte que no ha sido garantizada con la stipulatio) no puede ser suficiente, en orden a la intervención del Pretor, para sustituir eficazmente a la estipulación que falta, siendo negativa la decisión. No podría negarse la naturaleza de pactum que tendría el compromissum si el texto fuera clásico, cosa que no ocurre, como ha intentado poner de relieve Rotondi.

La conclusión última de La Pira será, por tanto, que la concepción del compromissum como pactum del que derivan exceptiones y actiones in factum, es típicamente justinianea. Considera interpolados otros pasajes como el siguiente:

Quod ait praetor: «pecuniam compromissam» accipere nos debere, non si utrimque poena nummaria sed et si alia res vice poenae, si quis arbitri sententia non steterit, promissa sit: et ita Pomponius scribit Iquid ergo si res apud arbitrum depositae sunt eo pacto, ut ei daret qui vicerit, vel ut eam rem daret, si non pareatur sententiae, an cogendus sit sententiam dicere? et puto cogendum tantundem et si quantitas certa ad hoc apud eum deponatur.] Proinde et si alter rem, alter pecuniam stipulanti promiserit, plenum compromissum est et cogetur sententiam dicere. ${ }^{28}$ 
Ahora bien, si el compromissum no es un pactum resulta evidente la afirmación de que no puede nudo pacto fieri compromissum, ya que tal afirmación es contradictoria, lo mismo que lo sería esta otra: nudo pacto stipulationem fieri. El intento de algunos autores de interpretar la afirmación de forma positiva, pensando en dos pacta de non petendo que habrían sustituido en este caso a las estipulaciones penales, no lo considera aceptable por cuanto las estipulaciones penales no son algo distinto del compromissum, sino precisamente el medio a través del cual éste se concluye. Así pues, o bien el compromissum tiene lugar necesariamente mediante dos estipulaciones (y en ese caso decir nudo pacto fit compromissum es afirmar algo contradictorio), o bien el compromissum puede hacerse también nudo pacto y entonces puede ser también un pactum. Pero, según se dijo anteriormente, la concepción del compromissum como pactum es típicamente justiniasnea..$^{29}$

Esta posición interpretativa, seguida por algunos romanistas ${ }^{30}$ es considerada por Talamanca como una consecuencia de un planteamiento no correcto de las relaciones entre conventio y stipulatio, en general, y de la regulación que tales relaciones tienen, en particular, en el caso del compromissum. ${ }^{31}$

El punto de partida de su razonamiento, pues, consiste en determinar con precisión las relaciones recíprocas entre conventio y stipulatio. Ante todo, subraya el hecho de que en la base de cualquier stipulatio, o de cualquier otro negocio abstracto y formal, existe una conventio, entendida como un acuerdo de las partes a propósito de un determinado conjunto de intereses que se pretenden con la stipulatio, siendo tal el sentido más probable de la conocida afirmación de Pedius citada por Ulpiano:

Ut eleganter Pedius ait, nullum esse contractum, nullam esse obligationem, quae non habeat in se conventionem, sive re sive verbis fiat. ${ }^{32}$

Esto supuesto, se trata de poner en evidencia la relevancia jurídica que pueda tener esta conventio sobre la validez o la eficacia de la stipulatio. El problema puede plantearse en dos direcciones: o bien intentar determinar hasta qué punto la conventio mantiene su autonomía respecto de la stipulatio, o también dentro de qué límites actúa sobre la 
validez o eficacia de la stipulatio misma. A este propósito, habrá que distinguir el tipo de estipulación que han empleado las partes, ya se trate de aquel mediante el cual asumen directamente los compromisos derivados del conjunto de intereses previamente dispuesto (y que puede dar lugar a una obligatio in dando o in faciendo), o de otro mediante el que asuman la obligación de pagar una determinada suma de dinero al verificarse una condición. ${ }^{33}$ Esta segunda hipótesis es la que presenta un mayor interés, ya que la problemática de las fuentes sobre el compromissum está siempre centrada en la stipulatio poenae, y es evidente que el conjunto de intereses dispuesto previamente por las partes «in tanto potrà avere direttamente influenza sull'efficacia della stipulatio, in quanto sia stato trasfuso in essa». ${ }^{34} \mathrm{~A}$ este propósito, es evidente que pueden darse una serie de casos concretos en los que se pase de la abstracción de la stipulatio (centum dare spondes) a la especificación en la stipulatio del conjunto de intereses existente entre las partes. ${ }^{35}$

Hay que tener presente, por otra parte, que la conventio puede seguir desplegando sus efectos únicamente sino es absorvida en la stipulatio, según pone de manifiesto el pasaje de Paulo citado anteriormente.

Supuesta la estructura de la stipulatio poenae, la interdependencia entre estos dos órdenes de problemas desaparece. La conventio sigue conservando sus efectos típicos de todo orden, teniendo una relevancia singular a este propósito el conocido pasaje de Paulo en que se dice:

Duo societatem coierunt ut gramaticam docerent, et quod ex eo artificio quaestus fecissent, commune eorum essent: de ea re quae voluerunt fieri in pacto convento societatis proscripserunt, deinde inter se his verbis stipulati sunt: haec, quae supra scripta sunt, ea ita dari fieri neque adversus ea fieri? si ea ita data facta non erunt, tum viginti milia dari? Quaesitum est, an, si quid contra factum esset, societatis actione agi posset. Respondit, si quidem pacto convento inter eos de societate facto ita stipulati essent: haec ita dari fieri spondesne? futurum fuisse ut, si novationis causa id fecissent, pro socio agi non possit, sed tota res in stipulationem translata videretur. Sed quoniam non ita essent stipulati ea ita dari fieri spondes?, sed si ea ita facta non essent, decem dari? non videri sibi rem in stipulationem pervenisse, sed dumtaxat poenam (non enim utriusque rei promissorem obligari, ut ea daret faceret et, si non fecisset, poenam sufferret) ed ideo societatis iudicio agi posse. ${ }^{36}$

A parte de la intervención evidente de los compiladores en este pasaje, ${ }^{37}$ hay que subrayar que el problema principal que en él se plan- 
tea consiste en la discordancia aparente entre el tenor de la estipulación recordada en el caso presentado a Alfeno y el que es propio de la stipulatio por la cual viene dada la decisión: mientras que el primero refleja una stipulatio penal accesoria, el segundo refleja una stipulatio penal principal. $^{38}$

La solución que Talamanca considera más exacta es que, a pesar de la aparente equivocidad de la segunda parte del pasaje citado, se trata de un solo y único caso concreto. El inciso que se inserta (non enim utriusque rei promissorem obligari, ut ea daret deceret et,si non fecisset, poenam sufferret) sirve a Alfeno para subrayar que en la stipulatio poenae añadida el promissor se obliga sólo al pago de la poena en el sentido de que la actio ex stipulatu puede ser ejercitada contra él únicamente para conseguir la poena. ${ }^{39}$

Según esto, la significación del pasaje es que no sólo esta doctrina tiene relevancia en el caso de la estipulación penal principal, sino también en la estipulación penal añadida, por la razón de que de ella nace una acción sólo para conseguir la poena, no para conseguir el interés. Arangio-Ruiz admite este planteamiento, pero excluye la eficacia absorvente de la stipulatio poenae añadida y piensa que puede justificarse la acción para conseguir solamente la poena basándose en la circunstancia de que después de las palabras ea ita dari fieri neque adversus ea fieri de la fórmula estipulatoria, no se encuentra la interrogación spondes?, que se refiriría sólo a la promissio poenae. Sin embargo, pienso que se trata de una hipótesis improbable, tanto por el extremo formalismo como por el hecho que aparecería extraño que, si esta hubiera sido la ratio decidendi, el jurista no hubiera hecho la más mínima mención a ella. ${ }^{40}$

Con el fin de justificar su posición interpretativa y poner de manifiesto la autonomía de la conventio respecto de la stipulatio, Talamanca pone su atención en otros pasajes del Digesto. Entre ellos, se refiere explícitamente a uno de Scaevola en que pone de manifiesto que la conventio, que está a la base de la stipulatio poenae, aunque esté desprovista de efectos obligatorios, mantiene siempre su autonomía en el sentido de que puede desarrollar los efectos que son sancionados en la cognitio extra ordinem. 
El contenido de este pasaje es el siguiente: Flavio Hermes donó por causa de manumisión el esclavo Stico y estipuló respecto a él del siguiente modo: «si el esclavo Stico que en este día te dí por causa de donación y de manumisión, no hubiere sido manumitido y liberado con la vindicta por ti y tu heredero, y esto no dejara de hacerse por dolo malo mío, Flavio Hermes estipuló que se darían cincuenta a título de pena, y lo prometió Claudio». Se pregunta: ¿puede Flavio Hermes demandar a Claudio por la libertas de Stico? Y se responde que nada se oponía a ello. Se pregunta asimismo si, habiendo querido el heredero de Flavio Hermes pedirle al heredero de Claudio que le diera a Stico la libertad, podía el heredero de Claudio dar tal libertad a Stico, con el fin de librarse de la pena. Y se responde que ello era posible. Por último, se pregunta si, no queriendo el heredero de Flavio Hermes litigar por esa causa con el heredero de Claudio, éste deberá dar la libertad a Stico en virtud de la convención (ex conventione) que medió entre Hermes y Claudio, según se demuestra con esta estipulación. Y se responde que debe darse esa libertad. ${ }^{+1}$

Pese a las dificultades de reconstrucción del caso concreto a que se refiere Scaevola, considero que debe preferirse la interpretación que da Haymann, en el sentido de que se trataría de una novación modal. ${ }^{+2} \mathrm{La}$ importancia del pasaje consistiría en que, aparte de la duración de los efectos propios de la conventio, en él se muestra cómo entendían los romanos la relación recíproca entre conventio y stipulatio, como se deduce de la frase ex conventione, quae fuit inter Hermetem et Claudium ut stipulatione supra scripta ostenditur.

Ahora bien, supuesta la autonomía de la conventio respecto de la stipulatio, debe ponerse de manifiesto cuál es la influencia de aquella sobre la eficacia de ésta, sobre todo en lo que se refiere a la commissio poenae, yendo más allá de las posiciones mantenidas anteriormente. ${ }^{43}$ Debe tenerse presente la naturaleza de negocio formal que conserva la stipulatio durante todo el período clásico, lo cual hace que los efectos que nacen de la misma estén condicionados por el tenor de la stipulatio misma. En otra palabras, la relación de la commissio poenae con la conventio, la eventual dependencia de ella de la valoración de la prestación que no se ha realizado y que con la stipulatio poenae se quería forzar 
de forma indirecta, depende únicamente de la configuración de la condicio stipulationis y de la circunstancia de si ésta constituye un momento idóneo de vinculación entre la commissio poenae y la disciplina del conjunto de intereses que subyace a la stipulatio.

. Talamanca distingue dos casos extremos en los que es posible delinear fácilmente el tratamiento de la commissio poenae, junto con otros casos intermedios en que esto es más difícil. Un primer caso es aquel en que las partes se refieren, como condicio de la commissio poenae, a la no ejecución de una prestación que se considera desvinculada del conjunto de intereses en que tiene una incidencia natural. Se trata de lo que puede llamarse «estipulación penal abstracta» y que se encuentra en pasajes como el siguiente:

Item si quis stipuletur: «si Pamphilum non dederis, centum dari spondes?...44

Otro es aquel en que las partes se prometen de forma unilateral o recíproca una pena para el caso en que se viole el conjunto de intereses que determinaron entre ellos, pudiendo llamarse «caso de estipulación penal accesoria» y que puede ejemplificarse en un pasaje de Paulo en que las partes hacen seguir al pactum conventum societatis una stipulatio: si ea ita data facta non erunt, tum viginti milia dari? ${ }^{45}$

Pues bien: lo que la doctrina anterior califica como tratamiento de la stipulatio poenae según el régimen de la condicio puede aplicarse sólo al caso de la estipulación penal abstracta en la que no existe vinculación con la conventio subyacente. Ahora bien, Talamanca subraya que esto no significa que en el otro caso, no se apliquen a la stipulatio poenae las normas sobre la condicio. Únicamente se afirma que la condicio está configurada de tal manera «che essa viene concretata unicamente dall'inadempienza, valutata secondo i criteri propri della conventio sottostante, degli impegni assunti con questa e non dal solo fatto del mancato verificarsi della prestazione dedotta in condicione. ${ }^{46}$

\subsection{Función de las stipulationes en el compromissum}

En su intento de demostrar la estructura estipulatoria del compromissum, La Pira sigue, en síntesis, el proceso siguiente: si el compromissum no es un pacto en sentido técnico, al tener como fundamento 
una conventio entre las partes, hay que deducir que se trata de uno de aquellos pacta que transeunt in aliud nomen, es decir, que adquieren consistencia jurídica al transfundirse en un negocio típico. En este caso concreto, ese negocio es la stipulatio. En otras palabras, el acuerdo que realizan las partes para someter a la decisión de un tercero una controversia adquiere relieve jurídico mediante la stipulatio, teniendo en cuenta, por otra parte, que serán necesarias tantas estipulaciones cuantas sean las partes que se comprometen. Todas estas estipulaciones, finalmente, están relacionadas entre sí; más aún: son elementos de un negocio que es el compromissum. ${ }^{47}$

La estructura clásica de éste, pues, sería la de un negocio formal, bilateral o plurilateral, concluido mediante dos o más estipulaciones con las que las partes someten una controversia a la decisión de un árbitro elegido por ellas, obligándose recíprocamente a respetar la sentencia.

En su intento de aportar pruebas en favor de la estructura estipulatoria del compromissum, La Pira destaca sobre todo el hecho de que los textos en que se hace referencia a él aluden siempre, de forma directa o indirecta a las estipulaciones que lo constituyen. La razón de ello la encuentra en el hecho de que la estructura estipulatoria del compromissum es la que se presupone en el edicto del Pretor, de cuyos comentarios se derivan estos textos. El edicto decía literalmente así:

Qui arbitrium pecunia compromissa receperit eum sententiam dicere cogam. ${ }^{48}$

Si no existía un compromissum, no intervenía el Pretor, ${ }^{49}$ y un compromissum existía únicamente cuando ambas partes se habían obligado recíprocamente mediante la stipulatio a someterse a la sentencia del árbitro. Especialmente significativo es, en este sentido, el siguiente pasaje de Ulpiano, citando a Pomponio:

si de meis solis controversiis sit compromissum, et de te poenam sim stipulatus, videndum, ne non sit compromissum; sed cui rei moveatur, non video. Nam si ideo, quia de unius controversiis solum compromissum est, nulla ratio est, licet enim et de una re compromittere; si vero ideo, quia ex altera duntaxat parte stipulatio intervenit, est ratio. Quamquami si petitor quis stipulatus est, possit dici, plenum esse compromissum, quia is, qui convenitur, tutus est veluti pacti exceptione; is, qui convenit, si arbitrio non pareatur, ha- 
bet stipulationem. Sed id verum esse non puto; neque enim sufficit exceptionem habere, ut arbiter sententiam dicere cogatur. ${ }^{50}$

Basándose en este texto, La Pira subraya, por una parte, que el compromissum supone las estipulaciones recíprocas de las partes, no siendo suficiente la stipulatio de una sola de ellas. En cuanto al modo de extinción, el compromissum revela de forma inequívoca su estructura estipulatoria, en cuanto que entre los modos de extinción del mismo es indicada también la acceptilatio. ${ }^{51}$ Esto demostraría que el compromissum es un negocio verbis contractum, puesto que non pot est verbis tolli quod non verbis contractum est. ${ }^{52}$

Finalmente, considera que es una consecuencia de la estructura estipulatoria del compromissum el hecho de que en él se aplica un principio que es característico de la stipulatio, a saber, aquel según el cual tot sunt stipulationes quot res. ${ }^{53}$ También en el compromissum, cuando tiene por objeto varias controversias no unidas entre ellas con unidad de causa, puede decirse que tot sunt compromissa quot controversiae. ${ }^{54}$

Desde una óptica diferente, y como punto de partida de su empeño de poner de manifiesto el carácter accesorio de las stipulationes compromissi, Talamanca observa que la conventio que subyace a las stipulationes penales tiene, en este caso, un contenido cuyos efectos pueden dividirse en dos categorías. Por una parte, la constitución del tribunal arbitral y la presentación al mismo de la controversia en los límites fijados por las partes y, por otro lado, el compromiso que éstas asumen a realizar los actos necesarios para que el proceso pueda culminar en la sentencia. ${ }^{55}$ Es evidente que los efectos vinculados a la primera categoría son siempre propios de la conventio compromissi y no pueden ser absorvidos ni siquiera por la eventual stipulatio in faciendo que las partes pudieran concluir respecto a las obligaciones asumidas en orden al proceso y a la sentencia. ${ }^{56}$

Esto supuesto, considera incomprensible que La Pira haya podido referir estos efectos al compromissum entendido como negocio completo, resultante de las recíprocas estipulaciones entre las partes. Literalmente afirma que «non ha neppure tentato di dimostrare come la giurispru- 
denza romana sia arrivata a concepire il compromissum come un unico negozio complesso sulla base dell'interdipendenza delle stipulazioni». ${ }^{57}$

Más trascendencia tiene para él otro problema que se plantea inmediatamente, a saber, el que hace referencia al momento de la unión entre conventio y stipulatio en el compromissum, en cuanto de él depende el carácter autónomo o accesorio de la stipulatio de la conventio subyacente. Y considera particularmente significativo a este propósito los dos documentos de compromissum que se conservan en las Tabulae Hercolanenses.$^{58}$ En el primero de ellos, es evidente que la stipulatio poenae es configurada como sanción del conjunto de intereses existente entre las partes y que es delimitado por la frase inicial Inter Castellianum et Seium controversia de finibus orta est et arbiter electus est, ut arbitratu eius res terminetur... ${ }^{59}$ Es especialmente interesante lo que se afirma más adelante: ... de ea controversia ita stipulati sunt itaque (pac)ti..., aunque se trata de una reconstrucción, Arangio-Ruiz y Pugliese-Caratelli consideran muy probable que sea la exacta. ${ }^{60}$

Una confirmación de esta doctrina se encuentra también en el siglo III, en una Constitución de Caracalla en la cual se lee:

Ex sententia arbitri, ex compromisso iure perfecto aditi, appellari non posse, saepe rescriptum est, quia nec iudicati actio inde praestari potest, et ob hoc invicem poena promittitur, ut metu eius a placitis non recedatur. Sed si ultra diem compromisso comprehensum iudicatum est, sententia nulla est, nec ullam poenam committi, qui ei non paruerit. ${ }^{61}$

Así pues, la poena sólo sirve para asegurar a las partes los efectos que la conventio compromissi no puede producir. Esto significa, en otras palabras, que su accesoriedad respecto a la conventio es evidente. Algunos autores, como Donatuti, ${ }^{62}$ aunque reconocían el carácter accesorio de la stipulatio poenae en este caso concreto, afirmaban, sin embargo, que se trataba de una estipulación penal añadida, ${ }^{63}$ afirmación que no puede admitirse porque, como afirma Talamanca, «alcun indizio non si può ricavare dal testo. $\rangle^{64}$

Por otra parte, hay que tener presente que, al referirse al compromissum, los juristas romanos nunca hacen referencia a la cuestión de la forma estipulatoria empleada, a propósito de las relaciones entre con- 
ventio y stipulatio, sino que siempre tratan el negocio en el sentido de considerar accesoria la estipulación respecto al conjunto de los intereses subyacentes. Esto puede y debe interpretarse en el sentido de que es suficiente la referencia al sententiae arbitri stari para que pueda deducirse que las partes han querido configurar las estipulaciones compromissi como accesorias a la conventio. ${ }^{65}$

Es también significativo a este propósito que Ulpiano afirme que la stipulatio compromissi in faciendo tiene como objeto, simplemente el sententiae stari:

Sed si poena non fuisset adiecta compromisso, sed simpliciter sententia stari quis promiserit, incerti adversus eum foret actio. ${ }^{66}$

Las fuentes ofrecen también otros datos que ilustran esta relación entre conventio y stipulationes poenae, al mismo tiempo que ponen de manifiesto la terminología empleada por los juristas romanos. Entre otros pasajes, es significativo, por ejemplo, el siguiente de Cicerón:

Ambitus redit immanis; numquam fuit par. Idib. Quint. faenus fuit bessibus ex triente coitione Memmi est quo cum Domitio; hanc Scaurus unum vincere Messala flaccet. Non dico vel HS centiens constituunt in praerogativa pronuntiare. Res ardet invidia. Tribunicii candidati compromiserunt HS quingenis in singulos apud $\mathrm{M}$. Catonem depositis petere eius arbitratu, ut, qui contra fecisset, ab eo condemnaretur. Quae quidem comitia si gratuita fuerint, ut putantur, plus unus Cato potuerit quam omnes leges omnesque iudices. ${ }^{67}$

Este pasaje de Cicerón se completa con otro del mismo autor que hace también referencia a los intereses propios de los candidatos al Tribunado y que, conjuntamente, ponen de manifiesto que las estipulaciones recíprocas no son la clave última para interpretar el significado del conjunto de intereses que están aquí en cuestión. ${ }^{68}$

Tras un análisis riguroso de estos parajes, hay que concluir que en la conciencia de una persona jurídicamente formada como era Cicerón, compromittere o compromissum se referían solamente al conjunto de intereses establecido previamente por las partes y a la designación de un árbitro que pusiera fin a una determinada controversia, sin tener ninguna relación con la forma estipulatoria. ${ }^{69}$ 
En este sentido es reveladora la afirmación que hace Ulpiano, y en la que distingue claramente entre el conjunto de intereses establecido por las partes (designado con el verbo compromiserit) y la stipulatio poenae correspondiente:

Item quaeritur si cum eo, a quo tibi sexaginta deberentur, compromiseris, deinde per imprudentiam poenam centum stipulatus fueris. ${ }^{71}$

Por otra parte, es indudable que esta forma de entender el compromissum encuentra una confirmación importante en la disciplina propia del mismo. Refiriéndose, por ejemplo, a algunas de las causas de extinción del compromiso, Paulo afirma:

Summa rei est, ut Praetor se non interponat, sive initio nullum sit compromissum, sive sit, sed pendeat, an ex eo poena exigi potest, sive postea deficiat poena compromisso soluto die, morte, acceptilatione, iudicio, pacto. ${ }^{71}$

Frente a la posición de La Pira que considera que en este pasaje la palabra pacto está interpolada, en cuanto correspondería en este caso, a la concepción bizantina, según la cual el compromissum es un pactum, ${ }^{72}$ Talamanca subraya que este razonamiento carece de base, ya que, al emplearse las estipulaciones penales de garantía para compromisos asumidos con la conventio, «se le parti operano una risoluzione per mutuo dissenso della stessa, ove questa sia ammisibile, venendo meno gli impegni che da questa derivano, non può più incorrersi nella poena». ${ }^{73}$

Hay que tener presente que Paulo está ocupándose en este pasaje del tipo común de compromissum, es decir, de aquel que se acompaña de recíprocas stipulationes poenae. Podría, en este sentido, plantearse le objeción de que el jurista se refiere únicamente a las condiciones de la intervención de la coërcitio pretoria, que dejan de tener relevancia cuando la garantía estipulatoria subsiste sólo respecto a una de las partes. Pero no es este el caso, ya que Paulo hace depender la solutio compromissi die, morte, acceptilatione, iudicio, pacto. $Y$, como observa Talamanca, entender la expresión compromisso soluto únicamente en el sentido de que cesa un compromiso idóneo para la intervención de la coërcitio pretoria, subsistiendo la eficacia de la stipulatio no extinguida (por ejemplo, de la acceptilatio o del pactum de non petendo), no pare- 
ce posible, en cuanto que si el término compromissum es empleado en el sentido de compromiso idóneo para obtener la coacción pretoria, cuando el jurista afirma compromissum solvitur, quiere indicar la extinción del compromiso y no sólo su carencia de idoneidad respecto a la coërcitio.

Más difícil es la interpretación del término iudicium en el pasaje de Paulo, causa de la ambigüedad de la expresión. Sin embargo, parece que deba excluirse totalmente que el jurista haya querido indicar con ella la deductio in iudicium de la pretensión expresada en el compromissum. En efecto, la deductio podía tener lugar de común acuerdo, y entonces podía plantearse el problema de si el comportamiento de las partes debía ser interpretado como una extinción del compromissum por consentimiento mutuo, ${ }^{74} \mathrm{o}$ bien por iniciativa de una sola de las partes. En este último caso el fundamento de la solutio compromissi era la commissio poenae, no la deductio in iudicium. Hay que tener presente además que la expresión usada por el jurista habría sido muy poco precisa para referirse a la litis contestatio sobre la pretensión comprometida. ${ }^{75}$

Además de los modos de extinción del compromissum a que se ha hecho referencia, y que se basan en un hecho extintivo de una de las dos estipulaciones penales accesorias al mismo, conviene tener presente otro más a que hace alusión Paulo con estas palabras:

semel commissa poena solvi compromissum rectius puto dici; nec amplius posse committi, nisi id actum sit, ut (in) singulas causas toties committatur. ${ }^{76}$

Para entender este pasaje y el significado real que le atribuye Paulo, hay que tener presente lo que afirma en otra ocasión, en sus Comentarios al Edicto, en el sentido de que si alguno dedujera en juicio el asunto sobre el cual se hubiera hecho el compromissum, no interviene el Pretor para obligar al árbitro a pronunciar la sentencia porque ya no puede haber pena. Pero si esto fuera así, sucederá que estaría en la facultad de quien se arrepintiera de haberse comprometido el eludir el compromiso. Por tanto, se habrá de imponer la pena y el pleito deberá continuar por sus trámites ante el juez:

Si quis rem, de qua compromissum sit, in iudicium deducat, quidam dicunt, Praetorem non intervenire ad cogendum arbitrum sententiam dicere, quia iam 
poena non potest esse, atque si solutum est compromissum. Sed si hoc obtinuerit, futurum est, ut in potestate eius, quem poenitet compromisisse, sit compromissum eludere. Ergo adversum eum poena committenda est lite apud iudicem suo ordine peragenda. ${ }^{77}$

Aunque la primera parte del pasaje, en la que la expresión quidam dicunt es ciertamente interpolada, parezca indicar que en la deductio in iudicium de la pretensión objeto del compromissum aparezca como una violación de éste, es indudable que se trata de un pasaje interpolado y que su significación se aclara teniendo presente la segunda parte del mismo. Sin embargo, algunos autores, entre ellos Rotondi, ${ }^{78}$ piensan que, en el derecho clásico, era posible plantear la cuestión de si la deductio in iudicium de la pretensión comprometida entrañaba o no tal violación. Más recientemente, parece imponerse como infundado tal planteamiento. En efecto, la función del compromissum es asegurar a las partes la solución de la controversia sin que tenga lugar la intervención de la jurisdicción ordinaria, y es evidente que el acudir a ésta es una violación del compromiso. Por tanto, el significado del pasaje y la opinión de los quidam a que se refiere Paulo deben entenderse en el sentido que el mismo jurista expresa en el pasaje anterior (D. 4,8,34,1). En otras palabras, la intervención del juez produce la commissio poenae y, por tal motivo, no puede ser constreñido el árbitro a pronunciar la sentencia, quia iam poena non potest esse. ${ }^{79}$

Por otra parte, Talamanca piensa que el problema concreto que se planteaba Paulo en el pasaje que cita $D$. 4.8.34.1 puede deducirse de las palabras finales del mismo: ... nisi id actum sit, ut (in) singulas causas toties committatur. A parte de la posibilidad de que las partes hubieran previsto de forma expresa la commissio poenae para cada una de las violaciones del compromissum, el jurista pudo plantearse el problema que se derivaba de la eventual aplicación a un caso concreto del principio enunciado por el mismo Paulo:

Idem respondit, quotiens pluribus specialiter pactis stipulatio una omnibus subicitur, quamvis una interrogatio et responsum unum subiciatur, tamen proinde haberi, ac si singulae species in stipulationem deductae fuissent. ${ }^{80}$

En el párrafo primero del texto, en que se afirma que siempre que habiéndose pactado muchas cosas se añade a todas ellas una estipula- 
ción, se establece que los acuerdos que tuvieron lugar durante el período previo a ella, se contienen en esa stipulatio, mientras que en el párrafo tercero se plantea un problema diferente, a saber si la única stipulatio, sujeta a una serie de acuerdos, debe entenderse como un único negocio o varios. Este problema, por otra parte, es tratado en una serie de pasajes en que es evidente la tendencia de la jurisprudencia romana a admitir una pluralidad de negocios cuando esto se corresponda con el interés práctico de las partes. Entre la compleja problemática tratada por los juristas romanos, puede hacerse referencia a algunos pasajes concretos. Ulpiano, por ejemplo, escribe:

Sed si mihi Pamphilum stipulanti tu Pamphilum et Stichum spoponderis, Stichi adiectionem pro supervacuo habendam puto; nam si tot sunt stipulationes, quod corpora, duae sunt quodammodo stipulationes, una utilis, alia inutilis; neque vitiatur utilis per hanc inutilem. ${ }^{81}$

Talamanca opina que un planteamiento semejante se hacía también para la stipulatio poenae, que desempeñaba una función de garantía para los compromisos asumidos por las partes. Y subraya que es evidente que si, bajo este punto de vista, se hubiera reconocido la posibilidad de una reiteración de la commissio poenae, no se podría haber llegado a la conclusión de que el compromissum debía considerarse extinguido. ${ }^{82}$ La solución que ofrece Paulo es negativa y se basaba, probablemente en la estructura de la stipulatio poenae, en cuanto que, en ella, a diferencia de la que ocurría en la stipulatio in faciendo, era uno sólo el objeto de la stipulatio, a saber, el pago de la suma de dinero cuando se verificara la conditio stipulationis. En este sentido, debe recordarse el siguiente pasaje de Ulpiano:

In hac stipulatione, quia plures causae sunt una quantitate conclusae, si committeretur statim stipulatio ex uno casu, amplius ex alio committi non potest. ${ }^{83}$

\subsection{Sentencia arbitral y sentencia judicial}

En su intento de poner de manifiesto lo que él considera identidad estructural entre arbitrium y iudicium, y tras haberse referido a la correspondencia que, según él, existe entre iudium y arbitrium y entre ius- 
sum iudicandi y receptum arbitrii, La Pira subraya igualmente la identidad entre sentencia arbitral y sentencia judicial.

Para poner de manifiesto las razones de su planteamiento, alude, por ejemplo, al hecho de que el arbiter como el iudex debe juzgar normalmente en unos determinados días. ${ }^{84}$ Igualmente, y a pesar del mandato del pretor, puede también jurar sibi de causa nondum liquere, haciéndose conceder más tiempo para deliberar:

Proinde si forte urgeatur a Praetore ad sententiam, aequissimum erit, si iuret sibi de causa nordum liquiere spatium ei ad pronuntiandum dari. 85

Asimismo la sentencia arbitral debe ser pronunciada, como la del juez, coram partibus ${ }^{86}$ Antes de la sentencia definitiva el arbiter puede publicar órdenes de preparatione causae, considerándose como tal la orden mediante la que intima a las partes su presencia ante él:

Unde videndum erit, an mutare sententiam possit? Et alias quidem est agitatum, si arbiter iussit dari, mox vetuit, utrum eo, quod iussit, an eo, quod vetuit, stari debeat? Et Sabinus quidem putavit, posse. Cassius sententiam magistri sui bene excusat, et ait Sabinus non de ea sensisse sententia, quae arbitrium finiat, sed de praeperatione causae, utputa si iussit litigatores Kalendis adesse, mox Idibus iubeat; nam mutare eum diem posse; ceterum si condemnavit vel absolvit, dum arbiter esse desierit, mutare se sententiam non posse. ${ }^{87}$

Además, y tal como ocurre con el juez, el arbiter no puede modificar su sentencia, ${ }^{88}$ debiendo coincidir esa sentencia, como la del iudex con el compromissum, ya que, según la expresión de Papiano, debe ser emitida secumdum forman compromissi, ${ }^{89}$ eliminando cualquier controversia. ${ }^{90}$

Igual que ocurre con la sentencia del iudex en el procedimiento ordinario, la sentencia arbitral puede contener: 1) como se deduce del siguiente pasaje de Ulpiano:

Si arbiter ita pronuntiasset, nihil videri Titium debere Seio, tametsi Seium non vetuisset petere, tamen si quid petiisset, videri contra sentiam arbitri fecisse; et id Ofilius et Trebatius responderunt. ${ }^{91}$ 
2) Una absolución o condena:

cum constet Titium Seio centum non debere Titium a Seio centum absolvo $0^{92}$ cum constet Titum Seio centum debere Titium Seio centum condemno. ${ }^{93}$

3) Una adiudicatio, como sucede, por ejemplo, en el pasaje siguiente:

Inter Castellianum et Seium controversia de finibus orta est, et arbiter electus est, ut arbitratu eius res terminetur; ipse sententiam dixit praesentibus partibus, et terminos posuit; quaesitum est, an, si ex parte Castelliani arbitro paritum non esset, poena ex compromisso commissa est? Respondi, si arbitrio paritum non esset in eo, quod utroque praesente arbitratus esset, poenam commissam..$^{94}$

4) Finalmente, tal como ocurría en la sentencia jusicial, ${ }^{95}$ la sentencia arbitral debía tener un contenido claramente determinado:

Pomponius ait, inutiliter arbitrum incertam sententiam dicere, utputa: «quantum ei debes, redde; divisioni vestrae stari placet; pro ea parte, quam creditoribus tuis solvisti, accipe». ${ }^{96}$

Desde otro punto de vista, La Pira ve en el carácter pecuniario de la condena una demostración evidente de la identidad entre la sentencia arbitral y la judicial.$^{97}$ Es decir, también en caso de compromissum relativo a una controversia real, el objeto de la condemnatio no es la res controvertida sino el equivalente pecuniario de ella. En controversias de esta naturaleza, el arbitrium, como ocurre en los correspondientes iudicia, lleva la cláusula arbitraria de restitución. Antes de promulgar la sentencia definitiva, el arbiter invita a la restitución de la cosa, del mismo modo que lo hace el juez, y sólo si esta invitación no es aceptada condena a la parte que no cumple al pago del equivalente pecuniario. El único pasaje en que fundamenta estas afirmaciones es el siguiente:

Arbiter intra certum diem restitui iussit, quibus non restitutis poenae causa fisco secundum forman compromissi condemnavit: ob eam sententiam fisco nihil adquiritur, sed nihilominus stipulationis poena committitur, quod ab arbitro statuto non sit obtemperatum. ${ }^{98}$

Contra el carácter pecuniario de la condena en la sentencia arbitral no puede aducirse un texto de condena in ipsam rem referido en el ya citado pasaje del Digesto en que se afirma: divisioni vestrae stare pla- 
cet ${ }^{99}$ La razón es que se trata aquí de una sentencia relativa a un arbitrium divisorium, y en éste no tiene necesariamente que existir una condena pecuniaria, sino que puede contener una simple adiudicatio. Eso mismo se hace evidente también en los correspondientes iudicia divisoria.

En efecto, en las Instituciones de Justiniano se lee, por ejemplo, el pasaje siguiente:

Si familiae erciscundae iudicio actum sit, singulas res singulis heredibus adiudicare debet, et, si in alterius persona praegravare videatur adiudicatio, debet hunc invicem coheredi certa pecunia, sicut iam dictum est, condemnare. Eo quoque nomine coheredi quisque suo condemnandus est, quod solus fructus hereditarii fundi perceperit, aut rem hereditariam corruperit aut consumserit. Quae quidem similiter inter plures quoque, quam duos coheredes subsequuntur. ${ }^{100}$

La identidad de principios que regulan la sentencia arbitral y la judicial se hace evidente, una vez más, en el carácter inapelable de las mismas. En el caso de la primera, debe recordarse el pasaje del Codex en que el Emperador Antonino recuerda a Nepociana que frecuentemente se respondió por rescriptos que no se puede apelar de la sentencia del árbitro al que se recurrió en virtud de un compromiso realizado conforme a derecho, porque tampoco se puede dar en virtud de ella la acción de cosa juzgada, y por eso se promete por ambas partes una pena, para que por medio de ella no actúe contra lo convenido:

Ex sentia arbitri, ex compromisso iure perfecto aditi, appellari non posse, saepe rescriptum est, quia nec iudicati actio inde praestari potest, et ob hoc invicem poena promittitur, ut metu eius a placitis non recedatur. Sed si ultra diem compromisso comprehensum indicatum est, sententia nulla est, nec ullam poenam committit, qui ei non paruerit. ${ }^{101}$

Este principio común de la inapelabilidad revela claramente la identidad de estructura de los institutos que están a la base del arbitrium y del iudicium, a saber, el compromissum y la litis contestatio. Con ambos, subraya La Pira, ${ }^{102}$ las partes únicamente han pretendido someter su controversia a una persona privada y someterse a su sentencia. Al ser promulgada ésta se alcanza el fin que se perseguía y termina el procedimiento. Incluso en el caso de que tal sentencia sea claramente injusta, no es más que la conclusión de aquello que las partes han queri- 
do mediante el compromissum o la litis contestatio. Por lo que, según afirma Ulpiano

Stari autem debet sententiae arbitri, quam de re dizerit, sive aequa, sive iniqua sit; et sibi imputet, qui compromisit. Nam et Divi Pii Rescripto adiicitur: «vel minus probabilem sententiam aequo animo ferre debet». ${ }^{103}$

La posición de La Pira a propósito de la identidad entre sentencia arbitral y sentencia judicial, basada en el carácter pecuniario de la condena, ha sido considerada por Talamanca como carente de base. ${ }^{104} \mathrm{Su}$ interpretación del texto citado de Papiniano es inexacta: ya en el siglo dieciocho la doctrina había puesto de manifiesto que la conventio compromissi preveía en el caso de la no restitución de los esclavos, la condena a una multa fiscal; a esta conventio se añadía la stipulatio con la que las partes se prometían recíprocamente la poena por el incumplimiento de las obligaciones asumidas. El pronunciamiento del árbitro en favor del fisco no corresponde, pues, a la condena pecuniaria sino que «deriva dalla particolare configurazione della fattispecie, in quanto era stata espressamente prevista dalle parti nella conventio compromissi». ${ }^{105}$

Por otra parte, no es fácil salvar a La Pira de contradicción evidente en sus afirmaciones. Si se sostiene que, en el caso concreto aludido por Papiniano, la stipulatio compromissi era concebida en favor del fisco, el árbitro que condenaba a la parte que no cumplía al pago de la poena habría emitido un veredicto inútil, ya que el arbiter ex compromisso no puede decretar la poena. He aquí cómo se expresa Ulpiano a este propósito:

Item si arbiter poenam ex compromisso peti vetuerit, in libro trigesimo tertio apud Pomponium scriptum habeo, non valere: et habet rationem, quia non de poena compromissum sit. ${ }^{106}$

Es preciso tener presente que Ulpiano no se refería en el párrafo final de este pasaje más que a la commissio de la poena que las partes se habían prometido recíprocamente. No se aludía, como creen algunos, a una hipotética conversión de la stipulatio en favor del fisco (que era ineficaz), en una stipulatio eficaz inter partes. Esto se deduce básicamente de la expresión secundum formam compromissi. ${ }^{107}$ 
Tampoco es convincente la posición de La Pira a la hora de explicar la posible función que tendría el carácter pecuniario de la condena. Según él, habría determinado el quanti ea res erit que era el objeto de la stipulatio poenae. Ahora bien, tal planteamiento está en contradicción con lo que se lee en las Tabulae Hercolanenses, aparte de no acomodarse a la terminología propia de las fuentes, en las que se hace referencia constante - como objeto de la stipulatio compromissi- a la poena que no abarca, en estricto rigor, también la promesa de una summa incerta, como el quanti ea res erit.

Hay otra razón, todavía más decisiva, que invalida el planteamiento de La Pira y es que el iudex de la actio ex stipulatu, con la que se tendía a conseguir el quanti ea res erit, no estaba en modo alguno vinculado por la decisión del árbitro. ${ }^{108}$ Es evidente, por otra parte, que a esta interpretación parece oponerse un pasaje de Javoleno en el que se dice:

Non ex omnibus causis, ex quibus arbitri paritum sententiae non est, poena ex compromisso committitur, sed ex his duntaxat, quae ad solutionem pecuniae, aut operam praebendam pertinent. Item contumaciam litigatoris arbiter punire poterit pecuniam eum adversario dare iubendo; quo in numero haberi non oportet, si testium nomina ex sententia arbitri exhibita non sunt. ${ }^{109}$

Hoy se considera indudable que la parte del texto idem... iubendo es un inciso que, por otra parte, no se relaciona directamente con el problema aquí planteado. Lo fundamental, según Talamanca, ${ }^{110}$ es que el jurista para determinar cuáles son los pronunciamientos del árbitro (cuya inodservancia produce la commissio poenae), los identifica con los que tienen por objeto una solutio pecuniae o un operam praebere, de este modo, habría distinguido Javoleno entre los pronunciamientos que definen el litigio (quae ad solutionem pecuniae pertinent) y aquellos otros que ad operam praebendam pertinent.

Hay que tener presente, en efecto, que la palabra sententia no tiene el valor exclusivo de decisión que define la controversia. Paulo, por ejemplo, recuerda un pasaje de Casio en que se distingue entre sententia quae arbitrio finiat, y sententia de preparatione causae:

Unde videndum erit, an mutare sententiam possit? Et alias quidem est agitatum, si arbiter iussit dari, mox vetuit, utrum eo, quod iussit, an eo, quod ve- 
tuit, stari debeat? Et Sabinus quidem putavit, posse. Cassius sententiam magistri sui bene excusat, et ait Sabinum non de ea sensisse sententia, quae arbitrium finiat, sed de praeparatione causae, utputa si iussit litigatores Kalendis adesse, mox Idibus iubeat; nam mutare eum diem posse; ceterum si condemnavit vel absolvit, dum arbiter esse desierit, mutare se sententiam non posse. ${ }^{111}$

Esto supuesto, y teniendo presente la distinción citada de Javoleno, cabe preguntarse si el contenido de la sentencia definitiva quedaba únicamente limitado al pago de una suma de dinero. Es indudable que existen sentencias arbitrales en que esto no ocurre, por ejemplo en los juicios divisorios, por lo que los posibles contenidos de la sentencia no se agotan en el ejemplo de Javoleno. En este sentido tiene una relevancia singular un pasaje de Paulo en que discute la validez de una sentencia que hubiera ordenado a las partes recurrir a otro árbitro o a la jurisdicción ordinaria, o hubiere impuesto una determinada satisdatio de acuerdo con el arbitrium de un tercero. En caso de que la sentencia del árbitro sólo pudiera contener la orden de pagar una determinada suma de dinero, no existiría siquiera posibilidad de plantear tal discusión y la motivación para excluir la validez de tal sentencia debería ser distinta de la que se apunta en este pasaje y que está fundada sobre la no existencia de una sentencia definitiva. El pasaje a que hacemos referencia es:

Quaesitum est de sententia dicenda, et dictum, non quamlibet, licet de quibusdam variatum sit; et puto vere non committi, si dicat, ad iudicem de hoc eundum vel se, vel alium (in) se, vel in alium compromittendum. Nam et Iulianus, impune non pareri, si iubeat ad alium arbitrum ire, ne finis non sit quod si hoc modo dixerit, ut arbitrii Publii Maevii fundus traderetur, aut satisdatio detur, parendum esse sententiae-; idem Pedius probat; ne propagentur arbitria, aut in alios interdum inimicos agentium transferantur, sua sententia finem controversiae eum imponere oportet; non autem finiri controversiam, quum aut differatur arbitrium, aut in alium transferatur, partemque sententiae esse, quemadmodum satisdetur, quibus fideiussoribus; idque delegari non posse, nisi ad hoc compromissum sit, ut arbiter statueret, cuius arbitratu satisdaretur. ${ }^{112}$

\subsection{Exceptio ex compromisso}

Una de las razones que suelen aducir quienes niegan al compromissum el carácter de pactum viene dada por el hecho de que las fuentes excluyen la exceptio pacti para tutelar los compromisos asumidos con 
el mismo. Los textos fundamentales son dos, uno de los cuales pertenece a Ulpiano y dice:

ex compromisso placet exceptionem non nasci, sed poenae petitionem. ${ }^{113}$

El otro ha sido conservado fuera de la compilación justinianea ${ }^{114} \mathrm{y}$ es éste:

Item ex corpore Gregoriani. Qui contra arbitri sententiam petit sola in eum poenae actio ex compromisso competit, non etiam exceptio pacti conventi. ${ }^{115}$

Supuesta la genuinidad de tales pasajes, ${ }^{116}$ es evidente que según ha puesto de relieve Roussier, ${ }^{117}$ tal era el régimen clásico, como se deduce de la circunstancia de que las fuentes se refieren como único medio de sanción del compromissum a la poenae petitio, a pesar de que sería admisible la exceptio pacti. Ulpiano, por ejemplo, dice:

Labeo ait, si compromisso facto sententia dicta est, quo quis a minore vigintiquinque annis tutelae absolveretur, ratum id a Praetore non habendum; neque poenae eo nomine commissae petitio dabitur. ${ }^{118}$

Paralelamente, Celso afirma también que, aunque el árbitro hubiera vetado que una parte reclamase a la otra, si el heredero hace la reclamación, incurrirá en la pena (poenam committet), puesto que no se acude a los árbitros para diferir los pleitos sino para poner fin a los mismos:

Quamvis arbiter alterum ab altero petere vetuit, si tamen heres petit, poenam committet; non enim differendarum litium causa, sed tollendarum ad arbitros itur. ${ }^{119}$

En su intento de determinar la razón última por la que la jurisprudencia clásica excluía la exceptio pacti del caso del compromissum, Talamanca observa que no se trata aquí del problema de si del compromissum, en cuanto conventio, surge una obligatio a sententia stari, en cuanto que el compromissum nunca es causa obligatoria típica, sino únicamente se plantea la cuestión de si, a través de la stipulatio, puede asumirse (en lugar de la obligación de pagar una pena en caso de transgresión de las obligaciones que se derivan de la conventio) la obligación, in faciendo, de cumplir la sentencia arbitral y, precedentemente, las obligaciones de naturaleza procesal que hacen posible que el árbitro pronuncie una sentencia válida. ${ }^{120}$ Esta posibilidad fue señalada por Ulpiano de forma expresa diciendo: 
Sed si poena non fuisset adiecta compromisso, sed simpliciter sententia stari quis promiserit, incerti adversum eum foret actio. ${ }^{121}$

EI sentido obvio de este pasaje es que, puesto que se ha prometido sólo el sententia stari, se deberá actuar contra la parte que no cumple con la actio incerti, ya que el objeto de la stipulatio es un facere, a no ser que se demuestre la existencia efectiva de un daño. En este sentido no parece tener consistencia la apelación que hace Roussier a la regla de la perpetuatio obligationis por efecto de la conducta dolosa del que promete. $^{122}$

Otros romanistas posteriores como Collinet y Schulz, ${ }^{123}$ que apoyan la posición mantenida por Rotondi ${ }^{124}$ restringen a la obligatio poenae la sanción jurídica que deriva del conjunto de intereses que han sido decididos previamente por las partes. Sin embargo, no precisan de qué depende esta restricción del compromissum al pago de la poena, aunque parecen atribuirla a la voluntad de las partes. En caso de que así fuera, no podía explicarse, entre otras cosas, por qué los juristas y emperadores rechazaron tan abiertamente la posibilidad de oponer la exceptio pacti ex compromisso.

Al intentar, pues, determinar la causa de tal exclusión, es más coherente, a mi juicio, la posición mantenida por Talamanca en el sentido de que es el resultado de la valoración dada al caso concreto por la interpretación de los iurisprudentes, aunque el fundamento de tal valoración no puede ser determinado de forma precisa, es importante tener presente la observación que hacía ya Declareuil a finales del siglo pasado, ${ }^{125}$ en el sentido de que la concesión de la exceptio pacti al demandado hubiera venido a alterar el equilibrio entre las partes. En efecto, para el demandante, del compromissum derivaba únicamente la actio ex stipulalatu para la poena, y no una acción para el cumplimiento de la sentencia; en cambio, el demandado absuelto que podía disfrutar alternativamente de la exceptio pacti y de la actio ex stipulatu habría tenido la posibilidad de elegir entre la exceptio y la acción para conseguir la pena. En cualquier caso, y tal como reconoce explícitamente Talamanca esta solución continúa siendo una simple hipótesis y «questo stadio non si può oltrepassare allo stato attuale delle nostre conoscenze». ${ }^{126}$ 
Es posible, en cualquier caso, hacer referencia a algunos textos de las fuentes que manifiestan, en otros casos, una preocupación evidente por mantener la sitiación de equilibrio entre las partes, en el caso de un compromissum acompañado de estipulaciones recíprocas. Piénsese, por ejemplo, en la decisión de Juliano que declara nula la cláusula de la mentio heredis unilateral, diciendo:

$\mathrm{Si}$ ab altera duntaxat parte heredis mentio comprehensa fuerit, compromissum solvetur morte cuisque ex litigatoribus; sicut solveretur altero mortuo, si neutrius heredis persona comprehenderetur. 127

Por otro lado, se ha pretendido por parte de algunos romanis$\operatorname{tas}^{12 x}$ que del hecho de que, en caso de ser violadas las obligaciones que se derivan del compromiso, las partes estén obligadas sólo al pago de la pena y no puedan recurrir a la exceptio pacti se deduce que las partes están obligadas solamente al pago de la poena y no a cada una de las prestaciones que estaban previstas en el compromissum. Para poner de manifiesto las razones por las que no parece exacta y fundada esta consideración, hay que observar, ante todo, que el compromissum no constituye una causa típica obligatoria, por lo que la mayor parte de los compromisos de las partes sólo pueden asegurarse mediante la coacción a través de la stipulatio poenae. La falta de un medio judicial para hacer valer el interés de la ejecución no excluye que las partes se comprometan a esos efectos, aun cuando tal compromiso no encuentre una sanción jurídica. Pero la crítica que pueda hacerse también a esa opinión es de carácter más general y se refiere también al caso en que los compromisos cuya violación da lugar a la commissio poenae pueden estar tutelados directamente por una acción o una excepción.

Piénsese, por ejemplo, en una stipulatio poenae como la que presenta Paulo: dos personas constituyeron sociedad para enseñar gramática y para que la ganancia que obtuvieran de esta actividad fuese común para ellos; consignaron en el pacto convenido de la sociedad lo que ellos decidieron que se hiciera, y después estipularon entre sí en los términos siguientes: lo que se ha escrito cúmplase de ese modo y no se haga nada contra ello. Y si de ese modo no se hubiera cumplido páganse veinte mil. Se pregunta ahora lo siguiente: si se hubiese hecho algo en contra, podría ejercitarse la actio societatis? Y se responde que si 
verdaderamente en el pacto realizado entre ellos respecto a la societas hubiesen estipulado de este modo: ¿prometes que así se cumplirá y hará esto?, habrá de suceder que si hubiesen hecho así por causa de novación, no podría ejercitarse la acción sino que consideraría transferido a la estipulación todo el negocio. Pero como no hubiera estipulado de esta manera: ¿Prometes que así cumplirá y hará esto? Sino diciendo: si así no se hiciere, dénse diez, no le parecía que en la estipulación se comprendió el negocio sino solamente la pena. Porque el que promete una y otra cosa no se obliga a cumplirla y a hacerla, y en caso de que no la hubiera hecho, a sufrir la pena, y por esto la actio societatis puede ser ejercitada (et ideo societatis iudicio agi posse). El texto original es:

Duo societatem coïerunt, ut grammaticam docerent, et quod ex eo artificio quaestus fecissent, commune eorum esset; de ea re quae voluerunt fieri, in pacto convento societatis proscripserunt; deinde inter se his verbis stipulati sunt: «haec quae supra scripta sunt, ea ita dari,fieri, neque adversus ea fieri; siea ita data, facta non erunt, tunc viginti millia dari»; quaesitum est, an, si quid contra factum esset, societatis actione agi posse? Respondit, si quidem pacto convento inter eos de societatis facto ita stipulati essent: «haec ita dari, fieri, spondes?», futurum fuisse, ut si novationis causa id fecissent, pro socio agi non posset, sed tota res in stipulationem translata videretur. Sed quoniam non ita essent stipulati: «ea ita dari, fieri, spondes», sed «si ita facta non essent, decem dari, non videri sibi, rem in stipulationem pervenisse, sed dumtaxat poenam; non enim utriusque rei promissorem obligari,ut ea daret, faceret, et si non fecisset,poenam sufferret, et ideo societatis iudicio agi posse. ${ }^{129}$

De acuerdo con este texto, los compromisos que derivan de la conventio están tutelados por la actio por socio, a través de la cual se obtiene el interés en orden al cumplimiento. Si en este caso las partes hubieran establecido que el que no cumpliera podía ser demandado únicamente con la actio ex stipulatu, esto no habría excluido que debieran sentirse obligadas a realizar las prestaciones que se derivan del pactum conventum societatis. Sólo quedaba excluido que, en caso de incumplimiento de una de las partes, la contraparte podía obtener el interés positivo, con la consecuencia de que la única sanción por el incumplimiento era la actio para el pago de la pena, pero ésta funcionaba como sanción por tal incumplimiento y presuponía, por tanto, que alguno de los compromisos asumidos no había sido cumplido. Tal incumplimiento se ha- 
bría valorado según las normas propias del contrato de sociedad. En cuanto al compromissum, Talamanca subraya que si en este caso los compromisos que se derivan de la conventio no son directamente coercibles (sino que sólo lo son parcialmente a través de la exceptio pacti), debe tenerse presente que la stipulatio poenae funciona aquí también como sanción por el incumplimiento de esos compromisos. Esto significa que se presupone la existencia de una conventio válida y que el incumplimiento de una de las obligaciones asumidas por las partes se valora según los criterios propios de esa conventio. ${ }^{130}$

\subsection{La concesión de la coërcitio pretoria en el compromissum}

Teniendo en cuenta el modo en que las partes han procedido para garantizar el cumplimiento de los acuerdos asumidos con el compromissum se plantea lógicamente la cuestión de determinar los límites dentro de los cuales se concedía la coërcitio pretoria.

En la stipulatio al quanti ea res erit, esa coërcitio era admisible. Y para entender las razones de ello, hay que tener presente que esa stipulatio es diversa de la stipulatio poenae, según se pone de manifiesto, en el siguiente de Ulpiano:

At si quis velit factum alienum promittere, poenam vel quanti ea res erit potest promittere. ${ }^{131}$

Esta contraposición se repite nuevamente en otro pasaje del mismo jurista en el que afirma:

Si procurator sisti aliquem sine poena stipulatus sit, potest defendi non suam, sed eius, cuius negotium gessit, utilitatem in ea re deduxisse: idque fortius dicendum, si quanti ea res sit stipulatio proponatur procuratoris. 132

En este mismo sentido se expresa también Neracio en un importante pasaje en el que dice que si el procurator estipuló que presentaría únicamente a aquel a quien estipulase, y no estipulara también la poena, sino hubiese sido presentado, esa estipulación no tiene ningún valor (propemodum nullius momenti est), porque al procurador, en lo que respecta a su propina utilidad, nada le importa que se presente (nihil interest sisti). Pero cuando al estipular hubiera tratado de un negocio ajeno, puede defenderse que se ha de atender en este caso no la utilidad 
del procurador sino de aquel cuius negotium gesserit, de modo que cuanto importó al dueño del pleito que se presentase, otro tanto se daba al procurador por aquella estipulación, no habiéndose presentado el reo. Lo mismo puede decirse, y con más razón, si el procurador hubiera estipulado de la forma siguiente: quanti ea res erit, para que interpretemos estas palabras no referidas a la utilidad del mismo, sed ad domini utilitatem:

Si procurator ita stipulatus est, ut sistat duntaxat eum, quem stipularetur, non etiam poenam, si status non esset, stipularetur, propemodum nullius momenti est ea stipulatio,quia procuratoris, quod ad ipsius utilitatem pertinet, nihil interest sisti. Sed quum alienum negotium in stipulando egerit, potest defendi non procuratoris, sed eius, cuis negotium gesserit, utilitatem in ea re spectandam esse; ut quantum domini litis interfuit sisti, tantum ex ea stipulatione non stato reo procuratori debeatur. Eadem et fortius adhuc dici possunt, si procurator ita stipulatus esset quanti ea res erir: ut hanc conceptionem verborum non ad ipsius, sed ad domini utilitatem relatam interpretemur. 133

Según subraya Talamanca, ${ }^{134}$ este pasaje de Neracio pone de manifiesto no sólo que la antítesis entre stipulatio poenae y stipulatio al quanti ea res erit era clásica, sino también la razón última por la que ambas estipulaciones diferían. En efecto, existe una analogía de estructura en cuanto a su forma exterior (promesa de una prestación para el caso de que no hubiera existido la realización de otra prestación) y en cuanto a su función (en lo que se refiere a la coërcitio en orden a la prestación in condicione). Pero difieren, en cambio, en la determinación del interés relativo a la prestación in condicione, que es característica de la stipulatio poenae, tal como pone de manifiesto, por ejemplo, el pasaje en que Modestino afirma que cuando se pide la poena ex compromisso, ha de ser condenado el que incurrió en ella, y no importa que a su adversario le haya interesado o no, arbitri sententia stari:

Quum poena ex compromisso petitur, is, qui commisit, damnandus est; nec interest, an adversarii eius interfuit, arbitri sententia stari, nec ne ${ }^{135}$

Hay que tener presente, por otra parte, que Ulpiano entiende el requisito de la pecunia compromissa como equivalencia al de la estipulación penal y admite también la coërcitio en el caso en que la res ha sido prometida vice poenae y en que la stipulatio funciona al modo en que 
lo hace la stipulatio poenae. ${ }^{136}$ Talamanca subraya que, al proceder así, la jurisprudencia hace un esfuerzo importante a fin de «extendere il più possibile l'intervento del pretore nei onfronti dell'arbitro renitente». ${ }^{137}$

Un ejemplo notable de ello le ofrece Ulpiano cuando dice que a veces el compromissum se hará válidamente nudo pacto; tal es el caso en que ambos fueron deudores y pactaron que no pida lo que se le debe aquel que no no haya obedecido a la sentencia del árbitro:

Interdum, ut Pomponius scribit,recte nudo pacto fiet compromissum; utputa si ambo debitores fuerunt, et pacti sunt, ne petat,quod sibi debetur, qui sententiae arbitri non paruit ${ }^{138}$

En cuanto a la coërcitio del pretor, en el caso de la stipulatio in faciendo, no parece posible que pudiera darse. Es cierto que en un pasaje del Digesto se lee la siguiente afirmación de Ulpiano:

Sed si poena non fuisset adiecta compromisso, sed simpliciter sententia stari quis promiserit, incerti adversus eum foret actio. ${ }^{139}$

Sin embargo, en este texto no se afirma que esa estipulación era idónea para obtener la coërcitio, ya que en él se habla únicamente de la commissio poenae en un momento en que ya ha dejado de hacer referencia a la coercitio. Por otra parte, hay una serie de circunstancias que ponen de manifiesto que no se cumplen las condiciones exigidas por la jurisprudencia para extender los límites de la intervención del pretor. Tal como resume Talamanca, falta la promesa de una suma de dinero, cierta o incierta, sobre la cual la coërcitio se admitía en el caso de la stipulatio al quanti ea res erit. Además, en la stipulatio in faciendo no se da la función de la stipulatio poenae que había servido para admitir la coërcitio en caso de que el objeto de la stipulatio condicional fuera algo distinto de dinero, o en el caso de pactos recíprocos de non petendo. Aunque, pues, no pueda establecerse una solución segura, parece coherente con el conjunto de los textos la no extensión de la coërcitio a las stipulationes in faciendo. ${ }^{140}$

Hay que observar, por otra parte, que el pasaje de Ulpiano que suele citarse para poner de manifiesto que existe un caso de compromissum capaz de producir la coërcitio pretoria fuera de la garantía de las estipulaciones recíprocas, es ciertamente interpolado, como reconocie- 
ron ya en su momento el propio La Pira ${ }^{141}$ y Roussier. ${ }^{142}$. El pasaje en cuestión decía:

Quod ait Praetor «pecuniam compromissam», accipere nos debere non si utrimque poena numaria, sed si et alia ares vice poenae, si quis arbitri sententia non steterit, promissa sit; et ita Pomponius scribit. Quid ergo, si res apud arbitrum depositae sunt eo pacto, ut ei daret, qui vicerit, vel ut eam rem daret, si non pareatur sententiae, an cogendus sit sententiam dicere? et puto cogendum, tantundem, et si quantitas certa ad hoc apud eum deponatur. Proinde et si alter rem, alter pecuniam stipulanti promiserit, plenum compromissum est, et cogeretur sententiam dicere. ${ }^{143}$

Aunque en este pasaje no es posible basarse para explicar cómo habrían podido los clásicos resolver el problema que se planteaba, a causa de su carácter interpolado, lo que no puede ignorarse es el hecho que en él se apunta de que, aparte de la intervención de la coërcitio, el acuerdo entre las partes podía, en un caso de esta naturaleza, desplegar los efectos que era capaz de producir, según las normas aplicables al negotium empleado.

Más importancia tiene otro pasaje de Ulpiano que recuerda una doctrina expuesta por Pomponio y según la cual, si el compromissum fuera únicamente sobre controversias mías y yo hubiese estipulado la pena, debía establecerse si no había compromissum. A esta cuestión responde diciendo que no ve la razón por la que se suscita tal duda. En efecto, si esto ocurre porque el compromissum es sólo sobre las controversias de uno, no existe motivo alguno, puesto que es lícito contraer un compromissum sobre una sola cosa. Esto supuesto completa su razonamiento diciendo:

si vero ideo, quia ex altera duntaxat parte stipulatio intervenit, est ratio. Quamquam si petitor quis stipulatus est, possit dici, plenum esse compromissum, quia is, qui convenitur, tutus est veluti pacti exceptione; is, qui convenit, si arbitrio non pareatur, habet stipulationem. Sed id verum esse non puto; neque enim sufficit exceptionem habere, ut arbiter sententiam dicere cogatur. ${ }^{144}$

Teniendo en cuenta la interpretación de este pasaje que hacía Rotondi, ${ }^{145}$ y que fue admitida por otros romanistas, debe decirse que la razón aducida por él para excluir la exceptio pacti, en el caso normal, no encuentra aplicación aquí. En efecto, el demandante no ha prometido poena, por lo que no se ve por qué pueda excluirse la exceptio pacti 
basándose únicamente en que él se habría limitado a prometer sólo la poena para el caso de contravención a la sentencia arbitral. Parece mucho más seguro, desde un punto de vista dogmático que, como resume Talamanca, la restricción de la sanción del incumplimiento de acuerdos asumidos por las partes con el compromissum al pago de la pena, tiene lugar por una valoración inspirada en el criterio de mantener el equilibrio entre las partes del negotium; igualmente, desaparece la razón de la exclusión de la exceptio pacti que se funda sobre ese mismo equilibrio y que está también condicionado por la subsistencia de las recíprocas estipulaciones penales. ${ }^{146}$

No cabe tampoco apoyarse en este texto de Ulpiano para afirmar que, al ser suficiente para la concesión de la coërcitio pretoria la exceptio que nacía del pactum de non petendo, el jurista no podía motivar aquí la exclusión de la coërcitio diciendo simplemente: neque enim sufficit exceptionem habere. El propio Rotondi admite que en este caso no se identifica la exceptio pacti de D. 4,8,11,3 con la exceptio pacti que nace del conjunto de intereses predispuesto por las partes. ${ }^{147} \mathrm{Al}$ admitir la coërcitio en el caso de un compromissum acompañado de dos pacta de non petendo, los juristas romanos, como subraya Talamanca, han mantenido la misma estructura que tiene el compromissum cuando se acompaña de las estipulaciones penales. ${ }^{148}$ Así pues, el pactum de non petendo debe tener como objeto otras pretensiones distintas de la que es objeto de compromissum, de igual modo que las estipulaciones penales aseguran a las partes una prestación distinta de aquella que éstas tienden a garantizar.

\section{NOT A S :}

1. Cf., entre otros, WEIZSÄCKER, Das röm. Schiedsrichteramt unter Vergleichung mit dem officium Iudicis, 1879.

2. M. TALAMANCA; Ricerche in tema di «compromissum», Milán, 1958.

3. G. ROTONDI, L'exceptio veluti pacti ex compromisso, Scr. giuridici, 1922, I, pp. 284 ss.. 
4. J. ROUSSIER, Du compromis sine poena en droit romain classique, en R.H.IV,S., 181939 , 167 ss.

5. G. LA PIRA, Compromissum et litis contestatio formulare, en St. Riccobono, 1936, II, pp. 189 ss.

6. IB., p. 189; como consecuencia de esta naturaleza de pactum, el compromissum habría permitido a las partes plantear libremente la controversia, sin recurrir a las formalidades orales y escritas que eran esenciales en el ordo indiciorum privatorum.

7. 'IB., p. 190.

8. IB., ib.; en efecto, la característica principal del proceso ordinario consistía en el planteamiento de la controversia según ciertos esquemas predeterminados hecha por las partes. Si tal planteamiento faltaba en el compromissum, no podía hablarse de un paralelismo del mismo con el proceso.

9. F. BONIFACIO, art. «Compromesso», Novss.D.III, p. 784.

10. Ib., 784; el autor añade que, al menos en el Derecho clásico, ninguna otra actio que no sea la de ex stipulatu nace de la decisión, por lo que no debe atribuirse más que un valor puramente descriptivo a la afirmación de Paulo según la cual compromissum ad similitudinem iudiciorum redigetur (D.4,8, de rec.,1), a menos que no se quiera sospechar de la genuinidad, tal como podría seguerir la expresión análoga de Justiniano quod iudicium imitatur (C.3,1, de iud. 14,1 a. 530).

11. M. TALAMANCA, Ricerche..., ed. cit., p. 3.

12. IB. 3-4. Talamanca observa que no es suficiente la constatación de que el compromissum, como la formula, sirve para fijar los límites de la controversia que se confía al arbiter, según afirma La Pira siguiendo a otros autores anteriores, ya que el hecho de que tal determinación debe tener lugar mediante el uso de concepciones verborum típicas se resuelve en una petición de principio. Según precisa Talamanca, la única consecuencia que se puede deducir es que pesa sobre las partes un onus de claridad cuyo fin único es eliminar controversias y posiciones encontradas. Finalmente, insiste en el hecho de que es infundada también la ulterior especificación de que los verba solemnia, que deben emplearse por las partes en las stipulationes compromissi, han de identificarse con los esquemas de las partes formularum.

13. LA PIRA, op. cit., pp. 215 ss.; el pasaje de Scaevola a que se alude (D. 4,8, 44) es el siguiente: Inter Castellianum et Seium controversia de finibus orta est et arbiter electus est, ut arbitratu eius res termineretur: ipse sententiam dixit praesentibus et terminos posuit: quaesitum est, an, si ex parte Castelliani arbitro paritum non esset, poena ex compromisso commissa est. Respondi, si arbitro paritum non esset in eo, quod utroque praesente arbitratus esset, poenam commissam.

14. El pasaje completo que cita Talamanca es:

[In controv]ersia quae est in[ter L. Cominium]

[Prim]um et[L.]Appuleium Proc[ulum de finibus]

[fundi] Numidiani qui est [L.] Comini Pr[imi et fun-]

[di Str]alt]anie[i]ani (?) qui est L. Appul[ei Proculi] 
[quod]que L. Appuleium Proculum [et L. Co-]

[miniu]m Primum [d]e ea cont[r]overs[ia in-]

[vicem sibi (?) de]beri praes[criptum sit (?)]

[... delberi pel---

[de ea controversia ita stipulati sunt ita]qu[e]

[pac]ti: quod Ti. Crass[ius Fi]r[m]us alr]bi-

[ter] ex compromisso inter L. Comini-

[um] Primum heredemve eius et [L. Appu-]

[leiu]m Proculum heredemve ciu[s]

[pallam coram utroque praesenti

[sen]tentiam prove sententia[[m]] dicat

[dici]ve i)u/beat et[[ante]] dum ante $K$.

[Feb]ruarias primas sente[nt]iam

[dic]at dicive i)u/beat diemque co[mpro-]

[mi]ssi proferat proferriv[e iubeat: si]

[quid ad]versus ea factu $/ \mathrm{m} /$ erit si[ve quid]

[ita] factum non erit HS M [p. r. d.)

[dol]umque malum huic rei ar[biterio-]

[que] abesse afutur[u]mque [esse] (TH 76)

15. M. TALAMANCA, Ricerche..,, p. 9.

16. IB., p. 10. El autor alude también a otros documentos de compromiso que se encuentran en las Tabulae Hercolanenses que ponen de manifiesto que existían, en la jurisprudencia cautelar, diversos formularios de compromiso relativos al modo de concretar en las stipulationes el conjunto de intereses predispuesto por las partes ( $T H$ 82; en este documento la estipulación penal se refiere a una serie de disposiciones en forma de proposiciones penales redactadas en primera persona, presentando la particularidad de ser concebida en forma subjetiva: stipulatus est L. Venidius Ennychus, spopondi eadem L. Annius Anicetus. Según Talamanca, la hipótesis más probable sobre la forma exterior del documento es que las diversas proposiciones penales estaban dirigidas por una proposición introductoria en la que se dejaba constancia de que entre el promitente y el estipulante se había alcanzado un acuerdo sobre un conjunto de interses que después se especificaban en las diversas cláusulas a través de las proposiciones finales mismas).

Otro formulario que se encuentra en las Tabulae Hercolanenses, aunque en condiciones pésimas es $T H 81$ que presenta la singularidad, respecto al citado $T H 76$, de que establece una conexión entre la promissio poenae y el conjunto de intereses que la misma tiende a asegurar. En este sentido, Talamanca opina que es probable que este documento reflejara un tipo ulterior de formulario de compromiso (IB. p. 18).

17. D. $4,8.1$.

18. CICERÓN, Pro Q. Roscio com. 11 .

19. BROGGINI, Iudex arbiterve, Killn Graz,1957, p. 201.

20. M. TALAMANCA, Ricerche..., p. 22; según él, las razones de quienes sostienen la opinión contraria se desvanecen teniendo presente otro pasaje de la misma oratio de Cicerón en que se lee:

Quae cum ita sint, quaero abs te quid ita de hac pecunia, de his ipsis HS ccc tuarum tabu- 
larum compromissum feceris, arbitrum sumpseris, quantum aequius melius sit dari repromittique, sic petieris (Ib. 12).

21. IB., p. 22. Teniendo esto presente, considera exacta la afirmación de Broggini, según el cual el paralelismo establecido por Cicerón no era entre procedimiento ordinario y procedimiento arbitral, sino entre las pretensiones que dan lugar a un iudicium strictum (en el cual el iudex sólo tiene un poder discrecional limitado) y las que dan lugar a un arbitrium, en el cual ese poder discrecional latissime manat. La contraposición, pues, se establece entre la naturaleza de las dos pretensiones, tanto si se hacían valer en el procedimiento ordinario o en el arbitral, pero no entre dos modi agendi (IB. p. 23).

22. Ibídem, p. 23.

23. D. $2,14,10, \$ 1$.

24. D. $2,14,7,4$.

25. D. 4,8,2: «Ex compromisso placet exceptionem non nasci, sed poenae potitionem».

26. G. LA PIRA, op. cit., p. 192.

27. D. $4,8,13, \$ 1$.

28. D. $4,8,11, \$ 2$.

29. G. LA PIRA, art. cit., p. 194.

30. Cfr. por ejemplo, E. BETTI, Sulla genesi storica del processo formolare, Per il XIV centenari della Codificazione giustinianea, Pavía, 1934, p, 457 y ss.

31. M. TALAMANCA, Ricerche..., edi. cit., p. 39.

32. D. $2,14,1,3$.

33. Hay que tener presente los dos tipos de stipulatio poenae que existen en Derecho Romano. Una de ellas tiene la forma siguiente: Si Pamphilum non dederis, centum dari spondes (en ella se promete la poena para el caso en que se verifique la condición); la otra es: Pamphilum dari spondes? Si non dederis, centum dari spondes? (esto es, en la stipulatio se especifica el conjunto de intereses y se promete el pago de la poena en caso de transgresión de los compromisos que se asumen.

34. M. TALAMANCA, Ricerche..., p. 41.

35. Téngase presente, por ejemplo, el pasaje de Paulo que se cita en D.17,2,71, prol.: Sed tota res in stipulationem translata videretur; Talamanca observa que es distinto el problema del tratamiento que recibe el conjunto de intereses que han dispuesto previamente las partes en el caso de absorción total en la stipulatio in dando et in faciendo (se trata de determinar si las obligaciones de las partes deben ser valoradas siguiendo criterios propios de la conventio absorvida en la stipulatio, o bien según el tenor de las cláusulas de la stipulatio. Aunque no existen fuentes explícitas, el autor piensa que, contrariamente al caso de la novatio de una obligatio bonae fidei (con la fórmula quidquid dare facere oportet ex fide bona), en el caso de absorción inicial los criterios de tratamiento de las obligaciones asumidas por las partes se toman del tenor de cada una de las cláusulas empleadas en la 
stipulatio en éstas, no puede, por otra parte, excluirse una referencia a la fides bona (Cfr. Ricerche..., p. 42, nota 18).

36. D. $17,2,71, \mathrm{pr}$.

37. Cfr. ARANGIO-RUIZ, La compravendita in diritto romano, Nápoles, 1954, p. 64, n. 3.

38. M. TALAMANCA, Ricerche..., p. 44.

39. La duda de que la stipulatio pudiera ser interpretada en el sentido opuesto no podía surgir en el caso de la estipulación penal principal, en la cual en modo alguno se podría pensar que el dare o el facere de la presentación deducida en la condición pudiera ser objeto de la actio ex stipulatu (IB. p. 45).

40. ARANGIO-RUIZ, La compravendita in diritto romano, Nápoles, 1954, p. 66. Por otra parte, tampoco favorece la hipótesis de Arangio el hecho de que, según consta en las fuentes, en todo caso de estipulación penal añadida, la actio ex stipulatu se dirigía exclusivamente a conseguir la pena, siendo significativo, por ejemplo, este pasaje de Paulo: Sed si navem fieri stipulatus sum et, si non feceris, centum, videndum utrum duae stipulationes sint, pura, et condicionalis, et existens sequentis condicio non tollat priorem? An vero transfeferat in se et quasi novatio prioris fiat? quod magis verum est $(D .44,7,44,6)$.

41. El texto de Scaevola (D. $45,1,122,2$ ) es el siguiente:

Flavius Hermes hominem Stichum manumissionis causa donavit et ita de eo stipulatus est: Si hominem Stichum, de quo agitur, quem hac die tibi donationis causa manumissionisque dedi, a te heredeque tuo manumissus vindictaque liberatus non erit, quod dolo malo meo non fiat, poenae nomine quiquaginta dari stipulatus est Flavius Hermes, spopondit Claudius. Quaero, an Flavius Hermes Claudium de libertate Stichi convenire potest? Respondit nihil proponi cur non potest. Item quaero, an, si Flavii Hermetis heres a Claudii herede poenam suprasecriptam petere voluerit, Claudii heres libertatem Sticho praestare possit, ut poena liberetur. Respondit, pose. Item quaero, si Flavii Hermetis heres cum Claudii herede ex causa suprascripta nolit agere, an nihilo minus Sticho libertas ex conventione, quae fuit inter Hermetem et Claudium, ut stipulatione suprascripta ostenditur, ab herede Claudii praestari debeat. Respondit, debere.

42. HAYMANN, Freilassungspflicht und Reurecht, Berlín, 1905, p. 18 ss.

43. Téngase en cuenta que el problema del tratamiento de la condicio de la stipulatio poenae se centró tradicionalmente en la alternativa del empleo de las normas que disciplinan la condicio, o bien sobre la alternativa de las normas relativas al incumplimiento de la obligación principal, en cuanto que la commissio poenae dependería del incumplimiento de ésta (Cfr., por ejemplo, DONATUTI, Di un punto controverso in materia di stipulazioni penali, SDHI, 1, 1935, p. 299 ss.; el autor admite la relevancia de la imputabilidad al deudor para el caso de la stipulatio poenae añadida y el régimen de la condicio para la stipulatio poenae principal).

44. D. $45,1,115,2$.

45. D. $17,2,71, \mathrm{pr}$.

46. M. TALAMANCA, Ricerche..., p. 58; el autor, teniendo presente la opinión de PEROZZI de que las reglas de la obligación condicional podían sustituirse con las dictadas por 
las partes, observa que esto es exacto en el sentido de que éstas pueden configurar libremente la condicio stipulationis, pero esto no significa que tal condicio no estuviera regulada por las normas relativas a la condición.

47. G. LA PIRA, Compromissum..., cit., p. 195. El autor resume su pensamiento afirmando que las estipulaciones compromissi son interdependientes y constituyen un negocio único: el compromissum, del cual se derivan los efectos propios de este instituto. Así, las partes están obligadas a someterse a la sentencia del árbitro únicamente si han concluido un compromissum, es decir, si se han obligado recíprocamente con una stipulatio. Por otra parte, el árbitro tiene obligación de pronunciar la sentencia sólo si se trata de un compromissum válidamente concluido.

48. D. 8,3, \$2; LENEL, Ed. 131 .

49. D. $4,8,11, \$ 1$.

50. D. $4,8,13, \$ 1$; véase también $D .4,8,11, \$ 3$ en donde Ulpiano recuerda, citando a Pomponio, que algunas veces el compromiso se hará válidamente nudo pacto, por ejemplo, si ambos fueron deudores y pactaron que no pida lo que se le debe aquel que no haya obedecido a la sentencia del árbitro.

51. D. 4,8,32, \$3... compromisso soluto die morte acceptilatione iudicio (pacto).

52. D. $46,4,8, \$ 3$. El contexto en que se hace esta afirmación es el siguiente: Aceptum fieri non potest, nisi quod verbis colligatum est; acceptilatio enim verborum obligationem tollit, quia et ipsa verbis fit; neque enim potest verbis tolli, quod non verbis contractum est.

53. D. $45,1,1, \$ 5$.

54. D. 4,8,21, pr.: Quid tamen, si de pluribus controversiis sumtus est nihil sibi communibus, et de una sententiam dixit, de aliis nondum; numquid desiit esse arbiter? Videamus igitur, an in prima controversia possit mutare sententiam, de qua iam dixerat. Et multum interest, de omnibus simul ut dicat sententiam, compromissum est, an non; nam si de omnibus, poterit mutare, nondum enim dixit sententiam; quod si ut separatim quasi plura sunt compromissa, et ideo, quantum ad illam controversiam pertinet, arbiter esse desierat.

55. M. TALAMANCA, Ricerche..., p. 66; ib. 102 ss.

56. El mismo autor observa que la eventual objeción de que los efectos de la conventio no sean tomados en consideración como tales, sino sólo en cuanto sirven para delimitar las obligaciones asumidas por las partes mediante la stipulatio, se resolvería en un sofisma en cuanto que las partes, con esa stipulatio se refieren precisamente, con el fin de delimitar sus compromisos, a la conventio; ésta, en lo que concierne a sus efectos no obligatorios, no puede ser absorvida por la forma estipulatoria y mantiene su autonomía, aunque sea tomada en consideración como contenido de la condición de una stipulatio in faciendo (Ib. p. 67, n. 59).

57. M. TALAMANCA, Ricerche..., p. 67; véase también en este sentido E. BETTI, Istituzioni, I, p. 276 n. 4; ARANGIO-RUIZ, Instituzioni, ed. cit., p. 334.

58. Cfr. TH 76 y TH. 82 .

59. TH. 76 . 
60. ARANGIO-RUIZ y PUGLIESE-CARATELli, Tabullae Herculanenses, $V$, en la Parola del Passato, 10, 1955, p. 450. Talamanca observa que, como ya habían visto los editores tal reconstrucción encuentra su fundamento en la ausencia de cualquier recuerdo, en ese documento, de las stipulationes y de las sponsiones, que en cambio se encuentra en todos los demás documentos, incluso en $T H$. 81. Su conclusión es que el carácter de conventio que es propio del compromissum recibe así una clara confirmación. Por otra parte, aunque la reconstrucción del formulario en $T H 82$ puede ser sólo conjetural, no puede desconocerse que la promissio poenae se refiere, como presupuesto de la commissio stipulationis, a los compromisos que se derivan del conjunto de intereses que se contienen en las cláusulas configuradas como proposiciones finales (Cfr. p. 69, n. 68).

61. C. 2, 55, 1 (a. 213 d. C.).

62. DONATUTI, Di un punto controverso in materia di stipulazioni penali, SDHI, 1, 1935, p. 304.

63. Ib. p. 306 .

64. M. TALAMANCA, Ricerche..., p. 70.

65. Cfr. WEIZSÄCKER, Das römische Schiedsrichteramt unter Vergleichung mit dem officium iudicis, Tübingen, 1879, p. 54.

66. D. $4,8,27,7$.

67. CICERÓN, Ad Quinctum fratrem, 2,14,4.

68. CICERÓN, Ad Atticum, 4,15,7: Tribunicii candidati iurarunt se arbitrio Catonis petituros. Apud eum HS quingena deposuerunt, ut qui a Catone damnatus esset id perderet et competitoribus tribueretur.

69. M. TALAMANCA, Ricerche..., p. 73.

70. D. $44,4,4,3$.

71. D. $4,8,32,3$.

72. G. LA PIRA, Compromissum..., cit., p. 194 y 197.

73. M. TALAMANCA, Ricerche..., cit., p. 74, n. 77.

74. Hay que tener presente la dificultad que podría entrañar a este propósito el siguiente pasaje de Ulpiano: Idem et si spreta eius ad iudicium litigatores ierint, mos ad eundem arbitrum redierint, praetorem non debere eum cogere inter eos disceptare, qui ei contumeliam hanc fecerunt, ut eum spernerent et ad alium irent (D.4,8,9,5 y 11 pr.).

75. La solución del problema estaría, según Talamanca, en la conexión de iudicio con acceptilatione y pacto (Ricerche..., p. 76).

76. D. $4,8,34,1$.

77. D. $4,8,30$.

78. ROTONDI, Un nuevo esempio di innovazioni pregiustinianee: l'excepttio veluti pacti ex compromisso, en «Scritti giur.», I, p. 293. 
79. A propósito del problema real que se planteaba Paulo en el pasaje citado de D.4,8,34,1, GUARNERI-CITATI piensa que se trataba de un compromissum que tenía por objeto varias controversias. El problema que plantea el jurista no es el de la commissio poenae respecto a una controversia sino a uno de los diversos compromisos asumidos por las partes con ese compromissum (Cfr. Studi sulle obbligazioni indivisibili in diritto tomano, $\mathrm{I}, \mathrm{Pa}-$ lermo, 1921, p. 213 ss.). En el mismo sentido, véase también, BESELER, Romanistische Studien, ZSS, 46, 1926, p. 92. Lo infundado de esta exposición interpretativa es puesto de manifiesto por Talamanca en Ricerche..., p. 78-79. El autor piensa que el problema que Paulo podía plantearse en este paseje no era sino la aplicación a un caso concreto de un principio enunciado por él mismo y que dice: Idem respondit, quotiens pluribus specialiter pactis stipulatio una omnibus subicitur, quamvis una interrogatio et responsum unum subiciatur, tamen proinde haberi, ac si singulae species in stipulationem deductae fuissent (D. $45,1,134,3)$.

80. D. $45,1,7,34,3$.

81. D. $45,1,1.5$.

82. M. TALAMANCA; Ricerche.... op. cit., p. 79.

83. D. 46,7,5,2. Teniendo en cuenta el carácter genuino de este pasaje (cfr. LA ROSA, La struttura della «cautio iudicatum solvi», Labeo, 2, 1956, p. 181 ss.), la aplicación de la regla stipulatio semel commissa amplius committi non potest, es relacionada claramente con la circunstancia de que las plures causae son sólo in condicione, y subsiste in obligatione únicamente la obligación de pagar la pena o el quanti ea res erit. Esta forma de funcionar la stipulatio compromissi adquiere una especial relevancia en relación con el compromissum de pluribus rebus al que alude ampliamente Ulpiano diciendo:

Quid tamen si de pluribus controversiis sumptus est nihil sibi communibus et de una sententia dixit, de aliis nondum, numquid desiit esse arbiter? Videanus igitur, an in prima controversia possit mutare sententiam, de qua iam dixerat. Et multum interest, de omnibus simul ut dicat sententiam compromissum est, an non: nam si de omnibus, poterit mutare (nondum enim dixit sententiam): quod et si separatim, quasi plura sunt compromissa, et ideo quantum ad illam controversiam pertinet, arbiter esse desierir (D.4,8,21 pr.).

84. Cfr. D. $4,8,13 \$ 3 ; 4,8,14 ; 21, \$ 5$.

85. D. $4,8,13, \$ 4$.

86. D. $4,8,19, \$ 2$.

87. D. $4,8,19, \$ 2$.

88. D. $42,1,55$.

89. D. $4,8,42$.

90. D. $4,8,19,1 \$ 2 ; 4,8,32, \$ 16$.

91. D. $4,8,21,1$.

92. D. $49,8,1, \$ 1$; cfr. D. $4,8,19, \$ 2$.

93. D. $49,8,1, \$ 1$; cfr. D. $4,8,19, \$ 2$. 
94. D. $4,8,44$; cfr. D. $4,8,21, \$ 3$.

95. D. $42,1,5, \$ 1$.

96. D. $4,8,21, \$ 3$.

97. G. LA PIRA, Compromissum..., art. cit., p. 223.

98. D. $4,8,42$. Recuérdese que el arbitrium de que habla Papiniano llevaba la siguiente cláusula penal: quanti ea res erit tantam pecuniam fisco Populi Romani dari spondesne? Según La Pira, la utilidad de la condemnatio a que se alude en el texto consiste de la promissio poenae por la cual, de forma indirecta, la parte vencedora tenía la posibilidad de actuar contra la otra.

99. D. $4,8,21, \$ 3$.

100. I. $4,18,4$.

101. C. $2,55,1$. A propósito de la sentencia judicial y de su carácter inapelable cfr. $D .4,8,32, \$ 14$.

102. LA PIRA, Compromissum..., art. cit., p. 223.

103. D. 4,8,27,2. En otro pasaje se lee también: ... Arbitrorum enim genera sunt duo: unum eiusmodi, ut, sive aequum sit, sive iniquum, parere debeamus, quod observatur, quum ex compromisso ad arbitrum itum est; alterum euismodi, ut ad boni viri arbitrium redigi debeat, etsi nominatim persona sit comprehensa,cuius arbitratu fiat $(D .17,2,76)$.

104. M. TALAMANCA, Ricerche..., op. cit., p. 29 ss.

105. M. TALAMANCA, Ricerche..., p. 30.

106. D. $4,8,21,4$.

107. En efecto, la adjudicación de la poena al fisco tiene lugar porque el árbitro había sido autorizado a ello por el compromissum. Esto excluye que la multa fiscal estuviera representada por la recíproca stipulatio poenae que las partes no habrían concebido si no es en favor del fisco. En efecto, en tal caso, secundum formam compromissi al árbitro no tenía ningún poder de pronunciarse sobre la poena. La multa fiscal era algo distintivo de la poena stipulationis a la que se hace referencia en el último párrafo del texto citado y su irrogación estaba prevista en el conjunto de intereses que la estipulación penal tendía a garantizar entre las partes.

108. Esto no impide recordar lo que se lee en un pasaje de Ulpiano:

Pomponius ait, inutiliter arbitrum incertam sententiam dicere, utputa: «quantum ei debes, redde; divisioni vestrae stari placet; pro ea parte, quam creditoribus tuis solvisti, accipe» $(D .4,8,20, \$ 3)$.

109. D. $4,8,39, p r$. Muchos intérpretes contemporáneos piensan que hay que mantener la opinión defendida por los Glosadores y según la cual al árbitro se le reconoce, en este caso, un verdadero poder de mulctam dicere. En igual sentido se expresan también los Basílicos $(7,2,39,1)$; igualmente autores del siglo XVI, como Baldo, o del siglo XVIII, como Cujas.

110. M. TALAMANCA, Ricerche..., p. 32-33. 
111. D. $4,8,19,2$.

112. D. $4,8,32,16$. Otro pasaje de Marciano que ayuda a comprender las razones que mueven a atribuir al texto de Javoleno una significación menos decisiva de la que tendría a primera vista, es el siguiente:

Si de re sua quis arbiter factus sit, sententiam dicere non potest, quia se facere iubeat aut petere prohibeat; neque autem imperare sibi neque se prohibere quisquam potest $(D .4,8,51)$.

113. D. $4,8,2$.

114. Cfr. TALAMANCA; Ricerche..., p. 101-102; F. BONIFACIO, art «compromesso», cit., p. 785 .

115. Consultatio, 9, 17.

116. G. ROTONDI, $L$ 'exceptio veluti pacti..., op. cit., p. 276. En el pasaje de Ulpiano el término placet que se emplea indica que los compiladores suprimieron probablemente un tratamiento más amplio, confirmando con autoridad la decisión que juzgaban más oportuna, de acuerdo con los principios bizantinos.

117. J. ROUSSIER, Du compromis..., art. cit., p. 170 ss.

118. D. $4,8,3, \mathrm{pr}$.

119. D. $4,8,37$.

120. M. TALAMANCA, Ricerche..., op. cit., p. 103.

121. D. $4,8,27,7$.

122. ROUSSIER, Du compromis..., op. cit., p. 179 ss.

123. COLlinet, La genèse du Digeste, du Code et des Institutes de Justinien, París, 1952, p, 128 ss. SCHULZ, Einführung in das Studium der Digesten, Tübingen, 1916, p. 121 ss.

124. ROTONDI, L'exceptio veluti pacti..., op. cit., p. 289 ss.

125. DECLAREUIL, Du compromis en droit romain et en droit francais, París, 1887, p. 49 ss.

126. M. TALAMANCA, Ricerche..., op. cit., p. 113.

127. D. $4,8,49,2$. Por otra parte, y como ya se observó anteriormente, es indudable la perplejidad de los juristas a causa del concurso entre la actio ex stipulatu para la pena y la exceptio pacti. Igualmente, debe tenerse presente lo que se dijo anteriormente a propósito de la fórmula placet, con la cual Ulpiano pretendía recoger la opinión dominante en la jurisprudencia imperial.

128. Cfr., por ejemplo, F. SCHULZ, Einführung in das Studium..., op. cit., p. 121 y ss.

129. D. $17,2,71, \mathrm{pr}$.

130. M. TALAMANCA, Ricerche.... op. cit., p. 116.

131. D. $45,1,38,2$. 
132. D. $45,1,81,1$.

133. D. $2,11,14$.

134. M. TALAMANCA, Ricerche..., p. 119.

135. D. $4,8,38$.

136. D. $4,8,11,2$.

137. M. TALAMANCA, Ricerche..., p. 122; esta extensión se pone de manifiesto, sobre todo, en el caso a que se refiere Ulpiano diciendo: Interdum, ut Pomponius scribit, recte nudo pacto fiet compromissum; utputa si ambo debitores fuerunt, et pacti sint, ne petat, quod sibi debetur, qui sententiae arbitri non paruit (D. 4,8,11,3).

Es importante observar que Ulpiano no quiere referirse con la expresión nudo pacto fiet compromissum a la conventio compromissi, sino al modo en que las partes asumen las garantías de los acuerdos contenidos en el compromissum. Como subraya Rotondi los nuda pacta sustituyen, en la economía del negocio constituido por la conventio y las estipulationes, a éstas últimas ( $L$ 'exceptio veluti pacti..., op. cit., p. 289 ss.). En suma, en este caso el requisito de la pecunia compromissa se ha entendido en un sentido muy lato admitiendo la coërcitio incluso en el caso en que, con otro negocio, se produzca un efecto análogo al que es propio de la stipulatio poenae.

138. D. $4,8,11,3$.

139. D. $4,8,27,7$.

140. TALAMANCA, Ricerche..., op. cit., p. 124.

141. G. LA PIRA, Compromissum et litis contestatio formulare, art. cit., p. 193 ss.

142. J. ROUSSIER, Du compromis sine poena, art. cit., p. 181.

143. D. $4,8,11,2$.

144. D. $4,8,13,1$.

145. G. ROTONDI, L'exceptio veluti pacti ex compromisso, art. cit., p. 285 ss.

146. M. TALAMANCA, Ricerche..., op. cit., p. 126 y 127.

147. G. ROTONDI, L'exceptio..., art. cit., p. 287.

148. M. TALAMANCA, Ricerche..., op. cit., p. 127-128; prolongando esta reflexión el autor considera que debe rechazarse también la opinión de MATTHIASS según la cual el pactum de non petendo podía tener también como objeto la pretensión litigiosa. Tampoco considera fundada la opinión de este autor según la cual ambas partes debían asumir la garantía de los propios compromisos con el mismo medio jurídico (por ejemplo, stipulatio o pactum de non petendo), apoyándose en el principio del equilibrio de las partes. En efecto, este planteamiento no se deduce de $D .4 .8 .11,3$, en el cual se subraya que ambas partes recurrieron al pactum de non petendo únicamente para ofrecer un ejemplo de un caso en que el compromissum se hizo totalmente al margen del recurso a la stipulatio. 
La conclusión última es, pues, que en el caso en que no tuviera lugar un pactum de non petendo, sino simplemente la exceptio que nacía de la configuración particular del negotium en el caso concreto, la coërcitio era negada. No tiene razón Rotondi, por tanto, cuando alude al origen oriental de la innovación que pretende descubrir en este pasaje. Talamanca cree que la motivación de Ulpiano no es infundada, pero necesita de una ulterior especificación que, probablemente se perdió a causa de los retoques de que fue objeto este pasaje por parte de los compiladores. 